\title{
Complex Systems Theory: Some Considerations for Sociology
}

\author{
Rosalia Condorelli \\ Department of Political and Social Sciences, Catania University, Via Vittorio Emanuele II 8, Catania, Italy \\ Email: rosalia.condorelli@tiscali.it, rcondor@unict.it
}

Received 13 June 2016; accepted 24 July 2016; published 27 July 2016

Copyright (C 2016 by author and Scientific Research Publishing Inc. This work is licensed under the Creative Commons Attribution International License (CC BY). http://creativecommons.org/licenses/by/4.0/

(c) (i) Open Access

\section{Abstract}

This essay presents a reflection on the main implications of Complexity Theory for science in general, redefining and dispelling myths of traditional science, and Sociology in particular, suggesting a redefinition of Parsons' classic concept of Social System, articulated around the property of self-maintenance of order rather than on its possible discontinuity and instability. It argues that Complexity Theory has established the limits of Classic Science, leading to a more realistic awareness of working and evolution mechanisms of Natural and Social Systems and showing the limits of our capacity to predict and control events. Dissipative structures have shown the creative role of time. Instability, emergence, surprise, unpredictability are the rule rather than the exception when systems move away from equilibrium (entropy), even if these processes are generated from a system's deterministic working mechanisms. Therefore, we have come to realize how constructive the contribution of Complexity is, in regards to the long lasting problem of the relationship between order and disorder. Today, the terms of this relationship have been re-specified in its new configuration of inter-relationship link, according to a unicum which finds its synthesis in selforganization and deterministic chaos concepts. From this perspective, as Prigogine suggested, studies on Complex Systems are heading toward a historical, biological conception of Physics, and a new alliance between natural systems and living, social systems. Non-linearity, far from equilibrium self-organization, emergence and surprise meet at all levels, as this paper attempts to highlight. In Sociology, insights of Complexity Theory have contributed to a new way of thinking about social systems, by re-addressing some fundamental issues starting to social system, emergence and change concepts. The current social system conception as complex dynamical systems is supported by a profitable use of non-liner models (in particular, the Logistic map) in the study of social processes.

\section{Keywords}

Complexity Theory, Complex Adaptive and Autopoietic Systems, Self-Organization, Emergence, 


\section{Surprise, Complex Social Systems, Complexity Theory in Sociology}

\section{Introduction}

Chance is the pseudonym God uses when He does not want to sign His name. (Anatole France, The Garden of Epicurus, 1895)

Is Complexity merely a fashion, a whim or a mania of the moment? Or is it a new theoretical and methodological paradigm to better understand our world? What happened to the end of science as Stephen Hawkin proclaimed over 30 years ago? Ilya Prigogine's answer to these questions is now shared by most scientists. "We are not at the end of science. We are at the end of the linear science potential, but we are at the beginning of a new science" (Presentation at the University of Illinois, 7 April, 1992). Therefore, we are not facing the moment's mania but rather the eclipse of the classic scientific, Galilean, Newtonian, Laplacian conception of linear determinism of reversibility, predictability and controllability of real phenomena. The scientific community is actually witnessing the rise of a new science, the Science of Complexity of dynamic systems and of its extreme manifestation, chaos. The new Science is celebrating the growing acknowledgement of non-linearity and, therefore, uncertainty, discontinuity, irregularity, unpredictability of real phenomena: to sum up in one word, their complexity.

The notion of complex systems is relatively new in the Social Sciences, but not so in the Natural Sciences. The Complexity Epistemological Paradigm reflects on the structure of the relationship among elements constituting a system. The novelty lies in a dual acknowledgement: the properties of non linearity of interactions among system components (non-proportional relationship between cause and effect whereby "small” initial variations in cause may produce "big”, unexpected, effects), and the properties of self-organization, evolution by adaptation and especially unpredictability of systems in their self-organizing process, due to interactional nonlinearity and positive feedback. Looking at systems as complex systems means, therefore, they are open systems, made up of many interacting elements in a Non-Linear way, and far-from-equilibrium systems (in a thermodynamic sense, namely maximum entropy) or dissipative structures, that is, instable structures, at the edge of chaos [1]-[3], in an intermediate state between complete order and complete disorder, able, in this intermediate state, to self-organize and evolve for adaptation in response to environmental perturbations, producing emergence, unexpected and unpredictable changes as result of nonlinearity of interactions and positive feedback. So, self-organization refers to the spontaneous emergence of order in complex systems, an order of non-equilibrium but also a non-static, unstable and unpredictable order, different from the state of asymptotic stability assumed from classical science. In a system governed by a linear causality and negative feedback, such as in the Newtonian classical conception, the whole dynamic of evolution tends to go off in a stable order and there is no place for surprise, for unexpected and surprising changes of internal system structures. Instead, in an anti-reductionist perspective, nonlinear interaction among system's constituent parts creates spontaneously self-organization, new patterns of relationships, a continuously new order, an emergent effect that is unexpected, surprising, and unpredictable as its properties are properties of the "whole" and not reducible to the sum of individual component behaviours or rather to the sum of individual interactions among components, considered one by one. The emergence concept implies, therefore, surprise and unpredictability.

Self-organization, emergence, novelty, surprise are the words used today to describe the new patterns of relationship, the new high-level properties of the system generated by collective dynamics of its components or by nonlinear interactions among its constituent parts [4] [5].

In other terms, a system's work and change mechanisms have been re-specified. The relationships between system components may change resulting in dramatic structural and behavioral changes (or bifurcations). Systems, although governed by deterministic laws, can be so sensitive to even the slightest changes from environmental circumstances that they appear unstable and discontinuous; positive feedback amplifies change, breaking up existing structures and behaviours, creating unexpected outcomes in the generation of new structures and behaviours. Thereby, continuously new structures, new stages of organization, and new orders, may emerge or even states of chaos, erratic and seemingly random behaviour, devoid of pattern (non-periodic behaviour) and of apparent order, in which uncertainty dominates and predictability breaks down (deterministic chaos). In this 
meaning, as we noted, complex systems are far-from-equilibrium systems or dissipative systems. They dynamically transform themselves from one moment to the next, forced to abandon their previous state of reference by internal instability and external perturbation. They then fluctuate between two or more new points of possible order, continuously and, therefore, irreversibly evolve into a new configuration (Prigogine's arrow of time), reorganize themselves around a new reference point and maintain it until a new perturbation once again pushes them into new evolutionary trajectories. Or else, they flow into chaos and can remain chaotic, and eventually destroy themselves. The case of Benard cells studied from Prigogine is illustrative of the behavior of complex systems or dissipative structures because of internal and external perturbations. Moreover, Prigogine considered Durkheim a forerunner of the dissipative structure concept in the social field, by interpreting the labor division process as a prove of spontaneous self-organization process of social system in response to society's moral and material density increase. Social ties instability (community, family and couple ties) due to modernization processes can be included in this theoretical framework too. All scenarios are possible, from increasing of social isolation and suicide, as Durkheim said, up to the current immunization processes to the weakening of social integration as spontaneous self-organization process (in this regard, see a Condorelli's current research, dated 2016 and cited in references).

It is now timely to clarify that what is called Complexity Theory is constituted by the convergence of several theoretical approaches. Regardless of different points of view and different systems under study (physio-chemical vs organic, living systems), there is a general point of contact. Indeed, the system's ability to adapt to continuous environmental disturbances by acquiring ordered, coherent, spatial and temporal structures without an external controller but simply on the basis of the pattern of interactions among its constituent elements, and the ability to evolve in time producing emergent, surprising, outcomes due to non linearity are acknowledged as the fundamental properties of Complex Systems by all approaches which on the whole constitute Complexity Theory: Dissipative Structures Theory [6], Complex Adaptive Systems Theory (the Santa Fè School) and Autopoietic Systems Theory [7].

It was, above all, research on dissipative systems (strange mixtures of chemical substances kept in a state of agitation which Prigogine studied in his laboratories, never reaching entropy, fluctuating continuously between various states and acquiring surprising configurations in their continuing process of self-organization) that showed that increase of entropy, imposed by the second law of thermodynamics does not necessarily create disorder in open systems. This research demonstrated time's creative role, and affirmed the dignity of irreversibility, in the most implicit meaning of evolution and ever new and impossible to foresee evolution outcomes. Research also underlined that irreversibility is the result of instability at the microscopic level and instability, emergence, surprise, unpredictability were the rule and not the exception when systems move away from equilibrium (Entropy). In this sense, Prigogine does not see degradation in the thermodynamic processes and in entropy production but an increase of complexity; in the dissipative structures he sees a place of a combination of order and disorder, and in time he sees creation and not dissipation.

The very same phenomenon of far-from-equilibrium self-organization has been described by the Theory of Complex Adaptive Systems, even though it is interpreted in light of "learning and selection" terms. The learning metaphor seemed to be appropriate for describing a behavior of a system able to self-organize, by learning from its environment, i.e. understanding its environment composed of other systems and adapting to the most meaningful perturbations by selecting, among all the possible forms of self-organization, the most suitable, and the most likely to ensure successful behavior in the new environmental conditions. Here, co-evolution and fitness landscape concepts mature, which refer to a mutual process of change between system and its environment as result of their interaction, and, therefore, to mutual impact of systems contrasted to the idea of a simple impact on a stable environment [3] [4]. Self-organization as a form of learning-adaptation and selection, on one hand, and non linearity and stabilization unpredictability, on the other hand, complete the scenario.

The centrality of the learning metaphor of the Adaptive System Theory is also shared by the Autopoietic System Theory. Formulated in Biology, it shifts its focus from formation and transformation of system organization, as in the two previous cases, to the way in which a system (especially if alive) manages to keep its identity and uniqueness. Hence, other new conceptualizations have been introduced such as: the concept of operational closure and ontogenesis, that is, the system's ability to adapt to the environment, changing its structure without loss its identity, structural coupling concept, as co-evolution between system and environment; the concept of self-organization as a cognitive process, as a process suggested and not determined by the environment to the system which decides which perturbation is significant for it and how to react according its structure, without losing its identity; the conceptualization of system autonomy, as a non-banal machine in which the relationship 
between input and output is filtered by the inner state of the system itself, so that for a given input the same output may not always correspond ${ }^{1}$ but there can be different outputs; and the Autopoiesis concept. From this perspective, unlike dissipative systems and adaptive systems, Autopoietic systems are able, not only to take on an ordered structure but also able to produce their own elements by themselves (for example, single-cell organisms).

On the whole, all these theoretical approaches have offered new conceptual instruments, whose resonance has been widespread in the Social Science fields as well. This new way of thinking about systems has influenced Sociology. According to Harvey and Reed [8], Social Systems are dissipative systems as well as natural systems. They can exhibit differentiation and self-organization processes, remaining far-from-equilibrium (entropy), and evolutions characterized by discontinuity, catastrophes, abrupt, sudden, unexpected, unpredictable, counterintuitive and apparently a-casual changes over time, according to the principle of temporal irreversibility. These features have encouraged the conceptualization of Social Systems as instable, Non-Linear dynamical systems or far-from-equilibrium systems.

Therefore, Crutchfield is right when he says that this new approach, centered on non linearity, has caused a "revolution” ([9], p. 22), involving numerous branches of science: Meteorology, Physics, Chemistry, Biology, Geology, Engineering, Medicine, as well as Economics, Sociology, and Political Science. The 'new' science is intrinsically interdisciplinary. It can describe fluid turbulence, earthquakes, epidemics as well as Stock Market crashes, Political and Social competition processes, population and crime dynamics, the spread of innovations, urban growth, or in general, the dynamics of new forms of social aggregation. In brief, today no social scientist will deny that social phenomena are not linear just as the planets' orbits are not linear [10]. Naturally, this does not mean that social phenomena are constantly chaotic but they do have a potential for positive feedback and chaotic interludes.

At this point, it seems we should define the meaning of the expression 'new science' more precisely. It is new in reference to the Newtonian conception of the universe. However, one might object that a fundamental discontinuity of natural and social processes is not a discovery tout court. In fact, Complexity has been theorized for over two thousand years, at least since the Greek atomists and the stoics. However, it was considered only in fundamentally intuitive terms. Likewise, Poincaré's original idea [11] of sensitive dependence on initial conditions and of its implications for predictions in Physics has lasted for decades, borrowing Ruelle's terminology, at the level of scientific philosophy. The real "novelty" now is that today we find ourselves in a more fortunate situation compared to Poincaré's and, before him, to Maxwell's situation. Due to ever more refined mathematical instruments (Topology studies, Ergodicity theory, Non-Linear differential equations) and computational instruments (ever more powerful electronic computers able to manage complex Non-Linear analysis programs and simulation software) we have at our disposal what was denied to the greatest minds of the past: that is, a theory that incorporates the possibility of controlling its theoretical assumptions. Put more simply, today, we can take into account unpredictability, formulate assertions on discontinuity of a certain phenomenon and ensure strict empirical control over these assertions. As was said above, extraordinary achievements have been recorded in the physical lato sensu sciences. Likewise, today, within the Social Sciences we are witnessing numerous applications in various fields of research (Economy, International Relations, Political Science, Social Psychology, Sociology, and Demographics), showing how surpassing a purely metaphorical use of the concept of chaos and complexity can finally be possible and actually workable.

This present clarification serves to clear up the field of a fundamental misunderstanding. To paraphrase Ruelle [12], Complexity becomes Science in the proper sense of Quantitative Science, when it is placed outside the realm of Scientific philosophy or of pure metaphor and is conducted by scientific investigation. Verifying that a system is a Complex System is, therefore, a necessary condition, otherwise complexity could be found everywhere. Hence, the relevance which Santa Fè Complexity theorists assigned to the process of building and testing of the Non-Linear generating mechanism of dynamic systems, where characteristics of complexity are perceived.

Is not by chance that the increasing success of Complexity Science lies on new mathematical modelling tech-

\footnotetext{
${ }^{1}$ In a banal machine the output depends only on the input and at the same input there is the same output. From The Autopoiesis Theory perspective, the system's structure has within itself the rules of its own transformation. The output depends not only on the input but also on the internal state of the machine itself. At the same input or perturbation, therefore, there can be different outputs (or system behaviors), according to the inner state of the machine (i.e. the structure it had before being disrupted). There are some differences in terminology between the Autopoiesis Theory, the Theory of Adaptive Systems and Dissipative Structure Theory. What this latter call organization, or the pattern of interactions among the elements or components constituting the system, is called structure. Instead, organization is considered the set of relationships among the elements that define the system's identity-its essential characteristics which cannot be lacking. The organization may take on different types of structures, different patterns of interaction that the system can take over without, however, losing its identity or organization. The structure is the physical materialization of the organization, the set of components and interactions that it tangibly produces. From this perspective, ontogenesis is the process of the system's structural change (equivalent to what is called process of self-organization in the other two theories) that takes place without the loss of system identity or organization.
} 
niques, which have shown us how intellectual linearism, inspired by Newton’s mechanics, has ended up by naively narrowing our view of nature and society.

We cannot however deny that Newton's physics, with its absolute space and time factors, has had a profound cultural impact. As we know, the Newtonian-Laplacian Weltanschauung gives us an image of the world, conceived like a gigantic clock, a gigantic "accurate” mechanism. As only a machine can be, it is endowed with perfection, reliability and working predictability. A deterministic operating mechanism, therefore, governs and makes system evolution predictable and even ensures the control over future events. The general assumption is that of a necessary structuring of phenomena as linear system, that is, governed by causal relationships of constant proportionality over time, and, therefore, stable, regular, incapable of any surprising and unexpected behaviour, predictable in their future manifestations. No wonder that, under the bounds of these natural rules, irregularities as well as atmospheric “disorder”, fluid turbulence, running faucets, falling leaves, stones rolling down a cliff, oscillations of magnetic waves and plant and animal population dynamics, heart beats, the diffusion of nervous impulses and so on, were considered brain teasers or, at worst, monstrosities by classic science [13].

After the age of Enlightenment and the revolution produced by Newton's approach to Physics, the Social Sciences also adopted linearity and, therefore, a vision of Social Systems that led to assume predictable outcomes, able to be manipulated according to a certain definition of public interest, proliferating at the time. As was justifiably noted, the birth of scientific public administration in the 1920's can only be explained by the assumption according to which a structured and rationally administered public service would lead to predictable outcomes [14]. Likewise, Keynesian Economic theory underlined the belief that macro-economic control through Politics was not only possible but desirable as well. Moreover, it is not a coincidence, as Elliott and Kiel [15] observed, that Skinner's Behaviourism, with its idea of almost unlimitedly malleable actors, originated in the $30 \mathrm{~s}$ and that Skinnerian research was published in Huxley's Brave New World.

The previous state of affairs was overturned when scientists became aware of the limitations inherent to linearity. Due to the development of modern calculators, only a few decades were needed to question the scientific trust in linear determinism which had lasted for three centuries,. Therefore, the New Science dissolved the association between linearism, determinism and predictability, celebrated in Laplace's universe, and represented an unpredictable and uncertain world.

Today, Physicists and Biologists recognize eternal turmoil as a constant reality in nature. And social scientists like Courtney Brown, author of a rigorous application of Non-Linear dynamics in the field of electoral volatility [16], does not hesitate to declare that there is no place in human existence where we cannot see complex Non-Linear dynamics operating and where the measure of our ability to predict and control is not seriously put into question.

However, if, on the one hand, an awareness emerges which scientific and cultural sensibility had not seen before, that is, the awareness of the limits of control and predictability, at the same time, on the other hand, Complexity Science is able to reach horizons that linearism could never reach: as we said, it shows that new forms of system self organization as well as chaos are nevertheless generated from a (Non-Linear) deterministic law. Therefore, determinism and predictability have to be kept distinct: the fundamental mechanism of the system can be deterministic (not implying stochastic elements) and yet it can produce essentially unpredictable, unexpected outcomes. Knowing the law that governs the system's behaviour does not necessarily mean that we can foresee its future behaviour. At the same time, the unpredictability of the system's evolution does not decree in itself the non-scientific nature of its studies.

By innovating, in respect to the concept of classical science, a science that defines itself as such in relationship to its ability to discover laws governing systems and to foresee phenomena change, predictability is no longer a test bench for assessing the scientific nature of research. The study of Complexity and Chaos celebrates a new ideal of science, a new scientific awareness that if, on one hand, understands it can no longer to be articulated on forecasting purposes for its own self definition, on the other hand, it models itself on the peremptory duty of accounting for mechanisms and laws which still structure and generate discontinuity.

This being stated, we believe that analyzing the theoretical and methodological implications of Complexity Theory for Sciences is very useful and suitable. This analysis constitutes the more significant aspect of this paper, which has two main objectives. To a higher level of generality, it presents an analytical framework of the principal implications of Complexity Theory for Sciences, redefining and discrediting various myths in mainstream Science. To a higher level of specificity, it proposes a reflection on the principal implications of Com- 
plexity Theory for Sociology, by investigating how its insights have contributed to re-address sociological debate on major issues such as social systems, emergence and social change concepts. In this regard, we shall see how Complex System Theory has led to redefining Parsons classic conception of social system which is articulated on the property of systemic stability (self-maintenance of order) rather than on its possible discontinuity and instability.

\section{The End of Certainty and the New Aim of Science}

The contents of contemporary scientific debate appear to be admirably summed up in the title of a well-known essay by Prigogine, dated 1997 [17]. The End of Certainty highlights how modern science celebrates through the concepts of complexity and chaos the dialectic synthesis of the opposition between two categories, scientifically and culturally conceived as mutually excluding one another: order-disorder, determinism-probability, being-becoming, necessity-freedom, determination-unpredictability, and constraint-possibility. This dialectical synthesis (expressed by the concept of deterministic chaos) characterizes the current scientific and cultural revolution, by revising the epistemological meaning of disorder, unpredictability, uncertainty, which are now converted into structural elements, that is, into inherent elements to the generator mechanism of real phenomena even if it is a deterministic mechanism.

The 'end of all certainty' expresses a new epistemological view, which gives us a picture of science less confident in its forecasting and controlling potentialities over events than the picture provided by the classic epistemological view. From Aristotle to Décartes, from Newton to Einstein, uncertainty was considered the daughter of ignorance. The lack of forecasting and events control was the result of the lack of the knowledge of the Law that generated them. Hence came the Enlightenment, Cartesian, Newtonian, Laplacian confidence in the ability of reason "to light up the darkness", to tear away the dark curtain of the unknown, to conquer with the light of reason what was obscure, to reclaim terrains of ever growing ignorance [18], affirming the realm of certainty, in other words, the realm of predictability and control over events. In the new epistemological panorama this trust is gone. Uncertainty is not considered sic et simpliciter a condition based on ignorance, nor as a condition depending on chance, in a huge cosmic lottery which assigns to events mere probability of occurrence. Instead, it seems a structural fact, which is intrinsic to the system. As research on Complex Systems has shown, it can spring from the law itself that structures the event, due to sensitivity of the system to initial condition changes and non linearity. Non-linearity amplifies even small changes in initial conditions of the system when it is in instability moments, so as to produce disproportionate, unexpected outcomes, escaping the capacity of prevision. So, at bifurcation points, the choice of one or other branch of the evolutionary process remains unpredictable, considering it impossible to master, control, and precisely define the system state, that is, its initial conditions and the very small changes in initial conditions to which the system continuously reacts. Even for complex systems consisting of few elements and described by well-known differential equations, system evolution, beyond a certain time horizon, remains unpredictable. Therefore, emergence, surprise, uncertainty, and unpredictability can be regarded as unavoidable conditions, which cannot be eliminated from the most intimate working mechanism of the system. Ignorance can regress, generating laws and mechanisms can be discovered, but all these cannot eliminate unpredictability, which remains inextricably linked to the orderly determinism of occurrences and of their Non-Linear cause and effect relationships. So, surprise and uncertainty are, according to Prigogine, inextricably part of human destiny, of nature and of human history ([19], p. 16). It is the End of certainty, in its most tragically disarming meaning for scientific undertakings which have always rooted their own aims, their own reasons, their own meaning in the most exalting project: making the uncertain certain, knowing order, to foresee and control the future, and the unknown. At the same time, however, it is also the beginning of a redefinition of science and its objectives.

Innovative in respect to the concept of classical science, the study of Complexity and Chaos, although it cannot articulate on forecasting purposes, revolves around the imperative of taking into account mechanisms and laws which structure and generate instability and emergence. Therefore, it is a Science that 'promises' and 'permits' us to better understand nature and the real behaviour of systems, physical systems, inorganic material, including living, human, social and mental systems [18]. In this regard, for example, Brown observes how linear determinism had dominated our thought processes to the point of preventing a more realistic representation of our human condition, whereas the comprehension of Non-Linear Complexity of our individual and collective lives gives us, without a doubt, the opportunity ... to no longer be passive riders on an evolutionary voyage that touches every level of our existence ([10], p. 146) and, thus, gain ... true freedom to determine our fate ... (p. 144). 
In fact, where is self determination among the blind (p. 144)? Statements like the preceding one are literally teeming on the pages of his Serpents in the Sand [10].

\section{Sensitive Dependence on Initial Conditions: The End of Big-Big}

In a true process of scientific and cultural renewal, an important implication that emanates from the Science of Complexity pertains to the so called "Big-Big" explanation strategy. This explanation strategy should be strongly revisited: "big” events do not need proportionally 'big' causes; simple laws do not necessarily lead to simple behaviours. The acknowledgement of complexity, that is, non linearity and thus instability, uncertainty and unpredictability of real phenomena, means that real phenomena may be characterized by non-proportional or nonlinear relationships of cause and effect and may, therefore, be particularly sensitive to even the slightest changes in initial conditions (c.d. butterfly effect): in Non-Linear systems any "small" change in the cause variable can produce a "big", non-proportional, change in the effect variable, just as a "big" change in the cause variable can generate a "small" change in the effect variable.

The Sensitive dependence on initial conditions, that is, the circumstance by which even the slightest change in initial conditions leads to a significant change in a system's evolution, constitutes the primary characteristic which distinguishes nonlinear systems from linear ones. The latter are structurally stable; they do not change their behavior under small perturbations (slight changes in initial conditions or parameters) but respond proportionally, so much so that the effects of perturbations are damped and remain contained over time. Consequently, "linear systems exhibit smooth, regular, and well-behaved motion" ([20], p. 5) and are resilient to any attempts of destabilization. Naturally, this is a guarantee of system predictability. In other words, from diverse and possible starting conditions, the trajectories — or the total amount of states assumed by the system — which depart from each one of these conditions oscillate closely near each other. In fact, whatever the point of departure is, there will be rather similar previsions. We might say, for example, with a high degree of probability that, regardless of initial conditions, the state of the system in the temporal instant $t_{100}$ has a value of $x$. However, in Non-Linear systems this is not so, especially when they are in a chaotic regime. These are structurally unstable systems and can change their behavior significantly with even the slightest perturbations, whose effect is not damped but may be amplified exponentially. Therefore, unlike linear systems, nonlinear systems can generate very complex behavior over time (stable, periodic and chaotic temporal behavior), occurring intermittently throughout the life of the system. During some time periods, behavior may reveal linear continuity. However, during other time periods, relationships between system components may change, resulting in sudden, dramatic structural and behavioral changes. Thus, the system becomes unpredictable in the long run, due to the fact that at bifurcation points, at critical turning points where the system becomes unstable and loses its previous state of adaptation, nonlinearity amplifies fluctuations, even small changes in initial conditions, and it is impossible to foresee, among different possible solutions, which branch of the evolution path will be undertaken. In other words, making predictions becomes intrinsically a non-sense. Poincaré wrote significant pages on dependence on initial conditions in Science and Method [11]. Similarly, the 'butterfly metaphor' was coined by Lorenz [21] precisely to explicate sensible dependence on initial conditions and the unpredictability of Non-Linear chaos systems, suggesting that weather systems are typical examples of unpredictable deterministic systems in the long term. What realistic change can the flapping of a butterfly's wings cause in atmospheric conditions? Yet, Lorenz says, the flapping of a butterfly's wings in Texas may generate a tornado in China.

Non-linearity and consequent system sensitivity to change in initial conditions are the basis of the Prigogine's reflection on time. Prigogine recovers its scientific dignity decreeing its irreversibility, contrasting with the classical conception of time reversibility. The Newtonian time reversibility conception expresses the idea that a system, taken back in time, tends to choose the same branch of evolution path in correspondence to a bifurcation point. On the contrary, while reversibility is equivalent to support the predictability of system behaviour, irreversibility supports the more realistic view of a surprising universe, meaning that, at bifurcation points, the choice is unpredictable even in apparently similar conditions. Prigogine's arrow of time frees the universe from the harness of absolute schematisms, without time, conceding nothing even to Einstein's conception of time as illusion.

The discovery that small changes can lead to unexpected and surprising changes of state would eventually convince various theorists to promote the reversal of the game rules: the general rule should be to expect non linearity everywhere and, afterwards, to note down the exceptions that stray from the rule, where system behavior 
is effectively linear [10]. According Sociologists, it would be, for example, very advantageous to remember this concept in the Political and Economic spheres. It would be like saying that the stakes is the chance to understand how neighboring cultures, with common historical origins, can differ dramatically even without a particularly serious reason. They simply may have just reached a point of bifurcation, at which point their cultural trajectories were particularly sensitive to small fluctuations of certain initial conditions [15]. Each behaves as well as a non-banal machine. Thus, all scenarios are possible, and unpredictability, uncertainty is the order of things. No one, no social analyst, politician or economist, can ever tell what will happen. For example, no one could have predicted the current crisis of nation States and the onset of new nationalisms in liberal European States produced by globalization of the market rational economy and mass media, or the collapse of the Weimar Republic because of the strengthening of the Nazi party in a fragmented and therefore fragile and unstable political environment, with tragic events that occurred in the second World war. This realization is certainly disarming. And yet, in the face of political and economic crises that accompany our social life, the lesson of the complexity teaches us to be more aware of the world we live in, to be mindful of emergent potential risks that can hide in events such as the onset of a new trend, a new technology, or a new party, not to be surprised facing the surprising, the unexpected and unpredictable, and to analyze non linearity of the political and economic life by attempting to identify many possible evolutionary scenarios.

\section{Anti-Reductionism and Social Emergentism on the Edge of Chaos}

Delving still further into this area, we fully understand how the acquisition of self-organization processes, positive feed-back, emergent properties, unpredictability, that is, of all those factors which generate and in which non linearity manifests itself, also means problematizing the pervasiveness of a reductionist/atomistic/individuallistic rather than holistic conception of real phenomena. There is no doubt that reductionism/individualism and linearism are mutually reinforcing concepts: individualism seems to have provided, so to speak, intellectual nourishment to the linearism and its pervasiveness, and vice versa. From this point of view, looking at the natural and social world from the perspective of the "complex thinking" paradigm, as Morin defined it in his famous Introduction to Complex Thinking [22], means recoding atavistic problems of science, in general, and of Sociology, in particular, by recognizing the "macro", and, above all, by solving through the cardinal concept of Emergentism the contraposition between micro and macro, between reductionism and holism. On one hand, surprise, emergent properties, and spontaneous self-organization are the building blocks of a scientific landscape that proposes itself in holistic and anti-reductionist terms. On rejecting the reductionism, the creative and adaptive process that springs from the edge of chaos reveals, in fact, that it is more than just the mere sum of its parts, producing incomprehensible emergent outcomes if they are traced back to the behavior of its individual components. On the other hand, there is a connection between macroscopic order and microscopic fluctuations. Emergence is explainable only in light of overall context of a combination of Non-Linear interactions linking the system components to each other into a "whole". Emergent outcomes, with new, unpredictable, unexpected and irreproducible characteristics spring forth from this combination of local Non-Linear interactions. An example of this is fluid turbulence, which cannot be attributed to the overlapping of many harmonic oscillations, each in itself simple. It is easy to understand how this mechanism of positive feedback, this game of complexity, increases as the system components and their connections increase.

Thus, Emergence, in the peculiar sense of Emergentism, intervenes to integrate reductionism and holism (from micro to macro and from macro to micro) into a single perspective. In general, from this perspective, micro Non-Linear interactions explain the emergence of macro-structures. This new structure, this new order, regulates, in turn, the interactions, till the change in environmental conditions-an external environmental disturbance-disorganizes the interactions which, in virtue of their non linearity and sensibility to initial condition change, become unstable, fluctuating between one or more states of possible order. The system is destabilized; it is driven by its instability to abandon its previous state of reference and to evolve toward a new configuration, a new structural model, which now intervenes to rebind parts of the system, and which will be kept till a new disturbance of sufficient strength and a new internal and external conjunction of conditions will once again push it toward a new evolutionary trajectory. For Sociology, as we shall see, this is a chance to reread the debate on classic dilemma of the relationship between micro and macro level of analysis, between action and structure. In this sense, Prigogine's work [6]-[17] appears to be an important reference point for contemporary analysis of social systems. In particular, for New Complex Social Systems Theories (Theory of Social Entropy, Luhmanian 
Autopoiesis Social Theory) which, innovating in respect to classic Parsonian Theory, refers to the notion of instability, non-equilibrium and, therefore, emergent and surprising self-organization, the fundamental rules of structuring mechanisms of social systems and of human organizations.

\section{Determinism and Unpredictability, Order and Chaos, Chance and Chaos}

From what has been said, the really revolutionary scope of the New Science is the celebration of a new, unexpected, perhaps paradoxical coexistence: the combination between order and chaos, determinism and unpredictability. For centuries and cultural heritage, order and disorder were conceived as irreducible terms of the same continuum. As already noted, the new science loosens the ties between determinism and predictability. The Newtonian-Laplacian weltanschauung portrayed the world as a machine with perfect, predictable clock-like precision. From this deterministic conception comes the predictability of phenomena over time. We all remember Laplace's famous saying, "give me the state of the universe at any given time and I will predict the future". Now, however, determinism and predictability have to be kept separated due to the discovery that even if behavior is unexpected, discontinuous, unpredictable, there are nevertheless deterministic laws involved in its unfolding.

This extraordinary discovery, that deterministic laws can produce behavior only apparently random, that disorder can spring from order in a view that does not separate them irreparably, makes the old issue of incompatibility between randomness and laws' determinism obsolete. In 1944, for example, in his famous letter to Max Born, Einstein wrote that not even the great success of quantum theory could convince him that randomness was at the base of everything. Einstein was convinced: God did not play dice with the world, rather everything obeys a law $[23]^{2}$. Today, the concept of deterministic chaos synthesizes the union between order and disorder. The mechanistic image of the universe is definitively deflagrated by this last concept. Moreover, it even manages to shake up the vision of the universe as a gigantic cosmic lottery. Chaos has nothing to do with chance. It is the result of the system's ability to evolve toward that critical state where its sensibility to initial conditions change is such that these changes, albeit extremely insignificant, inevitably push the system to a state of disorder. And, however, the randomness and a-causality of system behavior is only apparent, having been generated by the same mechanism which is also at the basis of the same system's stability states. Thus, a new metaphor has been coined in the Social Science fields to confirm just how interdisciplinary Complexity Science really is. It refers to a world where, like an immense desert, phenomena leave traces very much like those left by serpents on the sand [10]. But the traces left behind are only apparently erratic, discontinuous, random. They, in fact, obey specific laws of structure and evolution. In short, let us borrow Stewart's famous line, "God does indeed play dice and at the same time creates a universe totally dominated by laws and order" ([24], p. 8). A new mathematical landscape emerges by the concept of deterministic chaos, where it is senseless "to ask whether God is playing dice with the world but rather what the rules of His game are" ([24], p. 8).

Techniques of mathematical modelling (models of nonlinear equations, simulation models, such as genetic algorithms, artificial life, etc.) have been developed to analyze systems evolving in a discontinuous and sudden way, trying to model order, the deterministic nonlinear law, underpinning to disorder. The Santa Fe researchers have entrusted to Mathematical modelling the progress in the study of complex systems.

It is useless to say which innovative perspectives Complexity Theory opens to the Social Sciences, resolving order and disorder within the context of the same working deterministic mechanism. Concepts such as "stable system”, “unstable system”, "return to stability”, "system crises”, can finally be devoid of the metaphorical, intuitive meaning which they are usually used and find a way to possible empirical investigations. This possibility is ensured by the parameter estimation of the Non-Linear deterministic mechanisms (equations), with which describe and explain the developments of given social phenomenology as aggregate results of local interactions: at certain values, each one analytically determined and determinable, we can verify empirically whether the system is steady or whether it is about to pass from order to chaos.

All the above introduces us to the question of prediction.

\section{A New Conception of Predictability}

Of course, Non-Linear Complexity leads us to question the extent to which were are able to predict and control natural, social and political systems. Under certain conditions, system characteristics are more stable, and there-

\footnotetext{
${ }^{2}$ A. Einstein’s letter to Max Born, 7 September 1944—Einstein, A., Born, M. and Born, H. (1981) Scienza e Vita. Lettere 1926-1955 (transl. it. Scattone, G.). Einaudi, Torino.
} 
fore a possible intervention action can produce the expected outcomes. But under other conditions, prediction is definitively lost, and it is impossible to control the outcomes of any intervention action on social and natural systems. Hurricanes, heart attacks, earthquakes, like stock market crashes, political campaigns, wars, cocaine use, and so on, appear to be events out of our control. This being stated, we may ask whether insisting on Complexity and Chaos is actually a waste of time: Is not 'losing' oneself on the study of Non-Linear analytical instruments, only to come to the conclusion that the phenomena is...unpredictable, vain? In reality, the study of complexity teaches us a new way of understanding prediction. While it is true that we often are unable to forecast the evolution of a given phenomenon, the study of Non-Linear dynamics and chaos allows us to 'predict' what the conditions are in which a certain type of dynamic behaviour occurs. So, for example, we may not be able to accurately predict the evolution of a certain biological population, or the spread of a disease or the effects of an invention, the outcome of elections or social competitions, or the productivity of companies, however we may be able to know at what conditions (at what parameter values) a certain population becomes extinct, a disease disappears or reaches a stationary cycle or evolves in a completely random manner, a firm goes bankrupt, a political system becomes unstable, a war breaks out, or a group takes over another group. Now, this type of knowledge is much more important for intervention policies (social or non) than exact knowledge of future system evolution. In fact, an acquisition stating that natural or social systems are in a chaotic situation, by specifying the critical threshold where our possibility to control the event completely disappears, does not seem at all trivial. Having to avoid such a danger, knowing the critical threshold point at which a phenomenon goes into a chaotic regime is an absolutely precious information. By being aware of this threshold, it would be possible, for example, to plan eventual interventions so as to keep the system away from limit situations and as close to stable situations as possible. In other words, it is more important to know the level below which water pollution must be kept, avoiding fish population's erratic evolution until it becomes extinct, rather than knowing the exact number of fish in a lake.

Naturally, we are not implying that instability is always "necessarily negative” nor that stability is always "necessarily positive”. In medicine, for example, there are cases where chaotic instability, and not stability, is the indicator of a healthy organism (heart beats, neuronal activity, etc.). Likewise, from a political point of view, stability is not always expression of a socially desirable situation, such as in the case of authoritarian regimes.

In conclusion, we cannot see any reason to consider the study of tools that allow us to achieve these above mentioned acquisitions a waste of time. Within the framework of the Social Sciences, for example, it is difficult not to agree with statements like those of Elliott and Kiel, according to which "by better understanding the confluence of chance and determinism in social system evolution we may we better learn when and how to direct policy responses” ([15], p. 68).

We will get back to this topic with examples taken from the Social Sciences.

\section{Cultural Unification of Science}

Our final appeal goes toward the huge potential of cultural unification where natural and social sciences are involved.

As was said above, the transversality of the complexity construct makes physicists, chemists, and social researchers agree, creates, under the auspices of an identical process principle, a communality between the physical and social world being formerly, traditionally, unthinkable and untenable from the perspective of each side. What was traditionally considered separate objects of study — on one hand, the freedom of human action, with all its burdens of uncertainty and unpredictability, and, on the other hand, nature, with its inner order-had created a gap between the social and the natural sciences for centuries. Today, Complexity and Chaos Theory shows this gap to be highly artificial [6], redeeming the social sciences from being in a position of scientific minority, or, as Kiel and Elliott would say, in a position of scientific stepchild compared to the so called hard Sciences ([20], p. 3).

\section{Complex Systems Theory in Sociology}

\subsection{Implications of Complexity Theory for Sociology: Society as Complex Adaptive System or Emergent, Far-from-Equilibrium, System}

Advances of Complexity Theory in the conceptualization of systems have offered to Sociology new insights, addressing issues intrinsic to the debate sociological as well, starting to the system concept. A long tradition of sociological thought has faced with issues related to the conceptualization of social system, social change, social 
emergence, relationship between micro-macro levels of analysis. Investigating whether and how the new acquisitions of Complexity Theory have contributed to the developments of sociological debate on these fundamental issues means taking a double point of view: 1) identifying points of contact, parallelisms, between the two theoretical areas, on the one hand, 2) identifying how Complexity Theory has encouraged within sociological debate a re-thinking on major issues related to social systems., on the other hand.

From this perspective, the main contribution of Complex Systems Theory to Sociology lies in having promoted a re-thinking of the social system concept.

The concept of social system as complex system is relatively new in Sociology, but it has been from its outset sufficient to reconsider some aspects of Parsons' functionalism to which the success of system concept in Sociology is nevertheless due.

From this new theoretical perspective, the critical point has been identified in the equilibrium concept. It is considered from Parsons the foundational property of social system being defined as interdependence, an ordered, stabilized, embedded in social structures, interweaving of interactions among system components, contrasted with action randomness. Equilibrium expresses the ordered interdependence concept and the tendency of the system (of this ordered interdependence) to stability, that is, to the self-maintenance of order and return to a particular state of equilibrium if disturbed. Therefore, equilibrium is equated to social order or societal integration, and its self-maintenance is an essential part of its definition as well as of system definition.

This being stated, this system concept showed to be still influenced by epistemological deterministic linear Newtonian-Laplacian paradigm of classical science, a paradigm that the New General System Theory (Complexity and Chaos Theory) has today questioned encouraging its critical revision in all sciences including Sociology. As we said, the more Classical science looked at systems as governed by a linear causality, by proportional relationships of cause and effect, and maintained in stable order by control mechanisms such as negative feedback, liable to ensure prediction and control over events, the more contemporary scientific reflection, matured in the field of Natural Sciences (Physics and Biology), has gradually revealed the limits of the mechanistic and reductionist paradigm imposed by Newtonian Physics. Consequently, theoretical macro-sociological analysis of social system has proceeded to revise the linearity option involved in the structure of social interaction processes, and especially to cancel the claim constituted by the equilibrium concept [25].

According to Bailey [25], for example, on the one hand, the revision was needed because the equilibrium concept seemed misleading as it was used by Parsonsian functionalism, alluding inappropriately to a state of order or integration of the system rather than to a state of maximum entropy, maximum disorder or system dissolution/death according to its more correct scientific meaning established by Thermodynamics. In effect, according the second law of Thermodynamics equilibrium signifies not system integration but rather the opposite (entropy or system dissolution) describing closed systems rather than open systems. Equating societal equilibrium with order or societal integration, Parsons used a concept "which has implications that are the opposite of those desired" ([25], p. 12).

On the other hand, the revision was needed because the Parsonsian concept of ordered, stabilized interdependence (or equilibrium as social order/integration) implies and emphasize stability, self-maintance, the return to a particular state of equilibrium if disturbed. The result is the difficulty in addressing sudden, unexpected, disproportionate changes (substantially this is in line with the critical approach of conflict marxian theories to parsonsian functionalism, though criticisms were advanced with a specifically ideological content). Even starting from the consideration that Parsons, as Bailey pointed out ([25], uses the concept of stable or in equilibrium system in the meaning of homeostatic and not static system, the revision was needed because this conception is associated to the idea of a gradual, ordered change process, "following a determinate pattern rather than random variability relative to the starting point (moving equilibrium, which is exemplified by growth)” ([26], p. 107), endorsing a linear conception of social interaction and change processes. In the light of new insight of Complexity, because of its implications, in neither of the two senses (in entropy or stability and homeostasis meaning), did equilibrium appear however appropriate in describing social systems as far as they are open systems.

After von Bertalanffy ([27], Prigogine [6] [28] [29] [17], Maturana and Varela [7], the qualification of real systems as open systems, which exchange information and energy with external environment, has in fact fixed the foundational system properties in an instability condition and evolution by adaptation and surprise rather than in the tendency to asymptotic stability or in the tendency to the state of maximum entropy, of maximum disorder with minimal internal differentiation/organization (equilibrium in a thermodynamic sense, which is appropriate in describing closed system but not open systems such as social systems are and we ourselves are, 
from a biological standpoint and in our cognitive processes as well). This acknowledgement, which is the central acquisition of the current scientific-epistemological approach to the study of systems, in Sociology has encouraged to go beyond the Parsons' functionalism without renouncing to a macro-sociological analysis of society as a whole. It has led-and this is the more important implication of Complexity Theory for Sociology-to emphasize the sociological validity of the concept of social system as stabilized or ordered interaction or societal integration, being indispensable for Sociology, without the equilibrium property "with its myriad meaning and problems" ([25], p. 13).

Complexity has, therefore, offered Sociology new analytical instruments to conceptualize social systems.

Complexity epistemological paradigm, today, enjoys wide diffusion in the Social Sciences due to its usefulness to describe traits which, as Ball suggested [30]), appear peculiar to social systems as well as physical ones (instability, far from equilibrium self-organization, emergence, evolution for adaptation, irregularity and change unpredictability), unable, in this case as well, to be comprehended by traditional approaches based on the deterministic linear Newtonian-Laplacian paradigm.

As we said, today, the macro-sociological analysis of social systems recognizes that they are dissipatives structures [8], adaptive [31] and autopoietic complex systems. Bailey identifies their properties in being, as open systems, far-from-entropy or equilibrium systems [25]-[32], on the edge of the chaos or intermediate between order and disorder (neither too regular and predictable such as crystal molecules nor too random and chaotic such as the molecules of a gas tending toward entropy). Bailey, indeed, defined Social Entropy Theory his theoretical synthesis between Sociology and New Systems Theory [32]). Nonlinearity, self-organization, emergence, surprise, self-reproducing, co-evolution, fitness landscapes concepts are entered in the sociological language, structuring a new way of thinking about social systems as unstable systems, but able to adapt to stresses coming from environment by generating spontaneously (from inner guidelines rather than the imposition of form from the outside) organization and evolving into a new interaction structure, to a new pattern of meanings or social expectations, new emergent, unexpected, order patterns, and new communication through communication [33] [34]. Translated into more specific sociological terms, inputs enter the inter-exchange network of meanings and is processed by inter-agents, being able to activate nonlinear, disproportionate to causal inputs, signification processes, and, consequently, equally disproportionate and unpredictable behavioral effects, beyond the very intentions of the individual inter-agents.

By using insights from Complexity Theory, Luhmann [33] [34] applies the concepts of operative closure and autopoiesis to Social Systems. The result is a conceptualization where social systems such as communications systems are emergent and self-reproducing systems. The convergence and stabilization of meaning in social interactions, which is indispensable to form a social system and which is made difficult because of double contingency, emerges spontaneously by selection among many possible meanings. Produced Laws, money, power, love allows social actors to reduce complexity in different contexts of social interactions. Similarly to biological systems described by Maturana and Varela, where environment does not determine but only suggests selforganization and, therefore, change processes, the operative closure and autopoiesis concepts allows Luhmann to emphasize the autonomy and "non-banality" of social systems. The analogy is clear in highlighting that a perturbation may modify social systems only when it is recognized by the system itself, that is, when it becomes object of communication, and that, when a perturbation has entered into the autopoietic communication network, the system decides whether and how to react, whether and how to change, according to its structure, without losing its own identity, producing emergence and, therefore, difficult to predict self-organizing outcomes, new social structures. Even differentiation between system and environment refers to specifications of the Complexity Theory. A social system produces by itself its own elements by reproducing communications through communications, and in so doing it builds its own boundaries, differentiating from its environment and on the inside into functional subsystems, each of which treats all others as its own environment. The relationship between system and environment is in line with the co-evolution concept matured into complex adaptive system and autopoietic system theory.

The conception of a mutual impact among systems implied in the coevolution concept is consistent with sociological theorizations that bring into question a one-way direction causal impact (such as Marx's system theory with its unidirectional causal relationship between structure (economical system) and super-structure (political and cultural system)).

Insights of Complexity Theory in reconstructing the relationship between micro and macro (between parts and whole) by the emergence concept present interesting implications for Sociology. In Sociology the mi- 
cro-macro relationship (between action and structure) is a very controversial issue. In this respect, complexity theory has many points of contact with the sociological realism. The emergence concept in a holism perspective constitutes the point of contact. Therefore, the sociological debate on the micro-macro relationship finds in the new acquisitions of Complexity an important reference point, and, in some respects, a turning point.

As we said, Complexity Theory promotes a connectionist and anti-reductionist perspective. From this point of view, the interactive relationship does not simply unite the parts like in an aggregate but connects and mixes them up in a super ordered whole. In other words, they become a system in which and through which components are connected to each other and are considered a totality rather than separate entities. The rapport between the parts and the whole, at this point, implies a new determination of causal relationships. As we previously said, the whole influences the parts/components of the system, and every element can act upon the whole and can modify it (bottom-up process), pushing it into a new, unexpexcted, emergent, order, which will be maintained until a new disturbance pushes it to a new and unpredictable evolutionary direction, in a new structure, which in turn connects the parts in a new form (up-down process). Macrostructures (self-organizations) are an emergent effect, because their properties are more than the sum of the properties of single parts, but are generated by micro fluctuations. As Holland highlighted, "the behavior of the overall system cannot be obtained by summing the behavior of the constituent parts” ([4], p. 122). Emergence is an intrinsic attribute of system, inherent to its workìng mechanism, and, therefore, it is a property of the real, with causal power on micro behaviours yet irreducible to them (macro causal ontology). The reductionism is rejected, although the principle of generativity by micro of the properties emerging to macro level is recognized and accepted.

Thus, Complex systems Theory reconciles in some respects holism and reductionism, rejecting a strong reductionism. This possibility is presents in Sociology too.

Within Sociology there are several attempts to theorize a bi-directional causation link between micro and macro levels of analysis (between action and social structure), contrasted with classical sociological perspectives tending to emphasize only one of the two levels of analysis. In this regard, for example, structuralist and functionalist theories in the durkheimian and parsonsian tradition highlighted an up-down process, while micro-sociological theories such as rational choice theories, Homan's exchange theory, symbolic interactionism and phenomenological approach emphasized a bottom-up process (downwards conflation vs upwards conflation [35]). More current sociological approach maintained both levels of analysis, for example, Coleman's micro-macromicro linkage, Structuration Theory of Giddens. The emergence concept is, in this case as well, the concept used in order to express the link between individual and social structure, that is, according a holism perspective, in order to refer to collective phenomena that are collaboratively created by rational individuals yet are not reducible to individual actions and able to determine them (macro causal ontology), contrasted with reductionist micro perspectives (micro causal ontology), where emergent social properties can be explained by reducing them to individuals and their relationship, that is, to the sum of individual actions [36]. This perspective recognizes the self-reflexivity and rationality of social actors without losing the emergent character of social totality, being expressed by unexpected, counter-intuitive, unintended effects. We can say that, from this perspective, there are important points of rapprochement between Systems Theory and sociological theory. The bottom-up and up-down process in Complex Systems Theory corresponds to the micro-macro-micro logic and the emergence concept presents contact points with sociological realism [35]-[37]. In this sense, sociological debate has been enriched by the insights of Complexity Theory on the emergence conceptualization, the link between emergence and nonlinearity and the connectionism. Sociological interpretations of society as complex dynamical system, such as Luhmann, Bailey and Sawyer did [36], and which expressly emphasize the connection between Complex Systems Theory and sociological realism, such as Byrne [37] and Reed and Harvey [38] suggested, resolve social emergence issue in the sense of a spontaneous bottom-up self-organizing process, where local interactions, extending to the whole system, generate-as result of nonlinear social interactions and positive feedback-unexpected and unpredictable global effects, new order structures, new pattern of social expectations, which are beyond the intentions of each agent, and which cannot be explained reducing them at the properties of individual interactions since they constitute an "effect of the system" as a whole, as an organized and dynamic collective entity. By overcoming the opposition between holism and strong reductionism, this theoretical synthesis explains the paradox, counter-intuitive and non unintended effects, which are produced by rational actions. From this perspective, the fact that rational actions are able to generate effects which contradict them becomes a intrinsic possibility to the logic of system, to its autonomy. In holistic terms, this new emergent order is able to re-orients social actions (causal up-down process) until a new self-organization and change proc- 
esses.

It is evident that this way of conceiving the emergence affects the way of thinking about the social change.

The acquisitions of Complex Systems Theory on holism and reductionism, self-organization and emergence processes, and, therefore, on the link between order and disorder, have contributed to re-address the sociological debate on order and disorder in social change process, that is, between realism and postmodernism in this regard.

According to Harvey and Reed, applying the concept of dissipative structure or complex adaptive system to the study of society means looking at social systems as inherently historical entities whose evolution "is driven as much by internal instability as by external perturbation”([8], p. 306), using environmental feedback for learning and adaptation. And the same conditions of nonlinear interactions or sensitive dependence on initial conditions observed for natural systems have been acknowledged to be the foundation for their historicity. Prigogine said, for example, human history may be described by a succession of bifurcations as well ([19], p. 16). As Brown highlighted [16], this realization has introduced into Sociology an emergentist conception of social change which celebrates discontinuity and unpredictability and uncertainty of the process but recognizes that it is the result of non linearity underpinning the deterministic mechanism of evolution. Some sociological interpretations of complexity theory have used the theory to support realism, the stable order of sense idea in line with the Enlightenment, confident in the progress, conception of a deterministic world, with rational and objective, intrinsic order [37] [38], contrasted with interpretations using it to support a post-modern vision, emphasizing the lack of stable sources of sense and rational teleology of history, the dismissal of the possibility of social causality and systematic social inquiry in favor of the uncertainty, unpredictability and surprise. They have grasped the potential of complexity theory of going beyond this dichotomous conception, linking determinism, and unpredictability, order and disorder. From this perspective, the Reed and Harvey's theoretical position of complex realism synthesizes complexity theory and critical realism. It remains within the modernist programme of progressive thought, and rejects at the same time the canons of postmodernism and reductionist positivism [37] [38].

In other words, the Complexity Theory, by its conceptualization of nonlinearity, emergence, and of the relationship between order and disorder, has inspired a new way of thinking about the classic issue of inherent indeterminacy of human behaviour. On one hand, the Complexity approach has led to reaffirm this idea. On the other hand, however, it has led to re-specify this concept, acknowledging that it is far from meaning that any order or any structural explanation of social life cannot be found and that a dice toss is the fundamental engine driving social processes. According to Huckfeldt, for example, this is an epistemological naivety associated with an earlier era ([39], p. 431). "It is a mistake”, Huckfeldt noted, "to argue that seemingly infinite complexity is necessarily a repudiation either of deterministic argumentation or of a structural interpretation of social and political life” ([39], p. 429). Rather, In the light of the complexity perspective, this concept has meant acknowledging that complex and even seemingly stochastic behaviour can be fully generated by a determinate structure underlying the logic of human behaviour and, therefore, "its indeterminacy is just inherent to a particular structural mechanism underlying social interaction processes” ([39], p. 429), whose logic is embedded in the framework of nonlinear structuration. As said above, this linkage between order and disorder is the idea that is synthesized in the deterministic chaos concept,

As a result, the way of thinking about the aim of Social Sciences was influenced as well. Complexity's insights have contributed to strengthen sociological sensibility for the analysis of the deterministic structure and logic underlying human behaviour "including the logic and structure of indeterminacy” ([39], p. 431), being considered no longer a metaphysical element but a valuable conceptual tool in the analysis of social life. In other words, today, the Complexity Epistemological Paradigm has encouraged the sociological awareness that, although we cannot predict social phenomena, we must attempt to understand underlying mechanisms governing social phenomena by modelling nonlinear social interactions.

From a methodological point of view, this has meant using two strategies of analysis. The Multi-agent simulation strategy models interaction process between agents. Some macro constraints are introduced into model in reference to agent action (pattern of interaction, norms, informations), in order to grasp unintended macro dynamics being produced by micro interactions.

The second strategy, which is emphasized in this essay, is the Nonlinear Dynamical System Analysis. It does not model a population of interacting agents. Nonlinear equation systems model the system state changes in time on depending on the structure of the relationship between variables which is hypothesized. Compared to linearism, the directional shift is substantial.

Linearism led to a concept of change of social systems where the assumption of constant proportionality rela- 
tions between cause and effect (linearity logic, the more... the more, the more... the less) implied the conceptualization of a regular and predictable process, with linear trend patterns (constant growth/decline parameters) excluding the possibility of irregularities or temporal discontinuity. It was, for example, this conceptual model, with its consequential use of linear equations, which led Malthus to predict exponential population growth concluding that it would be unsustainable when compared to the arithmetic growth of resources. Today, Social Sciences and Sociology have disavowed the pervading existence of linear social change processes. Several studies have shown the validity of the new conceptual model of social change, presenting the effectiveness of deterministic nonlinear dynamical models in formalizing human interdependences and describing discontinuous processes of social change, beginning with the population's evolution and market instability, going on to phenomena such as political revolutions, voting and electoral shifts, crime dynamics, urban growth, spread of innovations, adolescent childbearing, marital instability, authoritarian attitudes (on these issues, see: [16] [40]-[49]). Many of these studies found, in particular, that social systems, with reference to their movements over time, fluctuate between different critical points (bifurcation points), rather than follow a direct path, presenting a bounded development process. In this process, human interdependences are structured according to a non linear logic of the logistics type, where the interplay among factors that promote growth and factors that act as restraints (such as in a game competition) contrasts the idea of a regular linear or exponential trend, which is the expression of cause and effect constant proportionality logic, and is able to result in unpredictable outcomes of social interaction relationships and irregular and instable trends of social change process (even chaotic processes).

\subsection{Modelling Nonlinear Dynamic Systems: The Logistic Model in Social Sciences and Its Implications}

Dynamical System Analysis is interested in how the system's state changes in time. From a sociological perspective, the dynamics of a social phenomenon at aggregate level (i.e. marriage, divorce, suicide, politics voting.) expresses the result of individual decision making processes and therefore of social interaction processes. Collectively, they produce an aggregate configuration of social phenomena. Insofar as these decision-making processes can be affected by broad social and cultural factors (as well as in the passage from pre-modern to modern society), dynamics of social phenomena at aggregate level expresses, in a tangible way, the onset of possible changes in the structure of social interactions and allows us to make inferences about cultural changes which might have influenced these possible changes in individual and social decision-making processes. Therefore, making a dynamical analysis of social systems expresses the attempt to model the structure and the logic of human behaviour and underlying mechanisms governing social interactions, which are responsible for changes in social phenomena at aggregate level in time.

Non-Linear Dynamical System Analysis caters to the new conception of systems as complex systems, which requires dynamic and nonlinear models to capture self organization processes occurring in non-equilibrium conditions, and, therefore, system evolution processes characterized by discontinuity, sudden and unexpected changes, viewed as jumping from branch to branch of the evolution path.

In the field of Physical Science, a few well-known examples are Lorenz's model for chaotic behavior of weather conditions, Rossler's equation for chemical reactions, and Couette-Taylor's model for thermodynamic flows. If we take a look at the soft sciences, we discover that even here the Complex and Chaos Theory has been used and applied successfully. The success derives from the widespread and profitable use of the Logistic map. Over thirty years ago, May, one of the major authorities in the study of dynamic behavior and logistic map, stated that outside the physical sciences, this Non-Linear model is the rule and not the exception, foreseeing its systematic and fruitful use in the Social Science field ([50], p. 467)

In effect, this is what actually happened. In fact, its use in the Social Sciences is highly pervasive. Every time a social phenomenon has been studied from a possible non-linear perspective, the Logistic map-just because it is able to include regions of predictable behavior, regions of chaos and transitions between such regionsappeared to be the most suitable for modeling its behavior and for reconstructing its underlying governing mechanism. As we said, this is precisely what happened in the study of social phenomena as population evolution, economic processes (price analysis, consumer consumption, relationship between company profits and advertising campaigns, between production/productivity and investments, financial market trends and complex competitive economy behaviour, Walrasian processes); in studies involving political processes, from political competition phenomena [51] to the arms race [40] [52]-[55]; and in Sociology, from drug use [43] to the spread of new technologies and information [56], crime and infant mortality [43], suicide evolutive dynamics [47]. 
It has, among other things, been the base model for a whole series of equations representing the most complex derivations. As Dixon [57] opportunely pointed out, we might even call it a real live logistic equations family. Some of the most well-known derivations have allowed complex social processes to be modeled. Specifically, some logistic structure variations of the predator-prey model type have been applied with a high degree of success. Furthermore, these equations have also been employed successfully in urban-regional growth/decline dynamics, in describing evolution dynamics of populations (predator) and incomes (prey) [58] [44]; in the studies of political competition, for so-called electoral volatility [16], and of political revolutions, for the study of the rapport between revolutions and State coercion [41], and in the analysis of social control processes [39] [42] [46].

As is known, Logistics is the result of an opportune adjustment by Verhulst of the Malthus' law for population growth. Malthus' law is a simple differential equation able to model population changes from t time to $t+1$ time by a mechanism expressing a "free", unlimited, growth process [50] [59] [60]. Indeed in the Malthusian Growth Model the growth population mechanism equals $a y_{t}$, and the growth rate $a$ is constant, that is, it does not change with either time or population. Solutions of a differential or difference equation can be approximated by Euler's method and they are much more accurate as smaller $h$ integration interval is. In some cases, exact solutions can be obtained using algebra and obtaining mathematical general law. Therefore, the following differential equation governs the population growth mechanism per $h \rightarrow 0$ :

$$
\mathrm{d} y / \mathrm{d} t=a y(t), \quad a=\text { constant } .
$$

In discrete terms, adapting the difference equation notation, we have the following equation:

$$
\Delta y(t) \text { or } y(t+1)-y(t)=a y(t) \quad(\Delta t=1)
$$

E.g.

$$
y(t+1)-y(t)=a y(t), \quad t=2004,2005, \cdots
$$

where $\Delta y(t)$ is the change in $y$ population between two adjacent time period $\left(y_{t+1}-y_{t}\right)$ and $y_{t}$ is the population at the beginning of the $i$-th interval of length 1 ( $\Delta t$ or $h=1$, data are measured year by year). Population at time $t+$ 1 depends solely on population at time $t$. It is linear function of $y_{t}$ because it is proportional to $y_{t}$ by a constant fraction or relationship of proportionality $(a)$. The graph of the derivative function is an upward or downward straight line. Consequently, any population satisfying the Malthus's population growth law grows exponentially with time (trajectory of solutions is an up or down curve line). Indeed, its exact solution is the following equation:

$$
y(t)=y_{0} \mathrm{e}^{a t}
$$

where $y_{t}$ is the variable indicating the value of population at time $t, y_{0}$ is the initial value of population, and $a$ is the constant growth rate of population. The exponentials equation "represent the solution of a linear onedimensional differential equation and as such arise in a variety of circumstances in which the rate of change of a variable is proportional to the value of the variable" [61], p. 157). As it is known, the exact solution of Malthusian model can be written as

$$
y(t)=y_{0} b^{t}
$$

where $b$ is the Anti-logarithm of $\mathrm{e}^{a}$ (if $a>1, b=1+$ growth rate $a$ )

Adapting the discrete notation

$$
y(t+1)=y(t)+a y(t) \quad(\Delta t=1)
$$

or again

$$
y(t+1)=b y(t) \text { where } b \text { is } y_{t+1} / y_{t}
$$

if $a>1, b$ is $1+a(1+$ growth rate $a)$, if $a<1, b$ is inferior to $1^{1}$. In turn, the equation $y(t+1)=b y(t)$ is equal to

$$
y(t+1)=y_{0} b^{t} \quad(b=1+a)^{n} .
$$

As was said above, the Malthus model structures an unrestrained growth process. However, when the population gets too large, Malthus' model cannot be very accurate, since the environment cannot support unlimited growth due to limited environmental resources. Several factors discourage further growth (limited living space 
and resources, competition among individual members for limited resources). Verhulst's correction of Malthus' model avoids this problem, since it reflects the fact that the population growth is the result of opposing forces: the forces encouraging growth and the forces acting as a restraint. Therefore, it includes a restraint, preventing an unlimited growth mechanism. This is obtained by adding to the second part of Equation (1) and its discrete version (Equation (2)) a negative term, the $-b y^{2}$ term:

$$
\mathrm{d} y / \mathrm{d} t=a y(t)-b y^{2}(t)
$$

or in discrete form

$$
\Delta y(t) \text { or } y(t+1)-y(t)=a y(t)-b y^{2}(t) \quad(\Delta t=1) .
$$

This model is called Logistic growth model and is a quadratic equation. The graph of the function (placing $x_{t}$ values in abscissa and derivates of the function in ordinate) is a parabola. As we said, it excludes an exponential, ad infinitum growth rate and describes a bounded system in its development implying a limit value (carrying capacity) beyond which the system no longer grows. In other terms, it reasonably expresses a limited growth process within the framework of a limited resource environment. So, the $y^{2}$ term assures the self-regulation of the population if it gets too big. The restraint parameter $b$ is a limiting rate expressing the set of factors that discourage the population growth. Generally, $b$ will be very small compared to $a$, so that if $y$ is not too large then the term $-b y^{2}$ will be negligible compared to ay and the population will growth exponentially. If $y$ is very large, the term $b y^{2}$ is no longer negligible, and thus serves to slow down the rapid rate of increase of the population. In this way, a feedback is introduced into the system: population growth is now governed not only by a free growth mechanism but also by an adjustment mechanism competing with free growth, whose action depends on the interaction between system state (population at a given time) and environmental resources. In other words, this interaction determines the system's carrying capacity (the maximum value that population can reach, compatibly with available environmental resources). The presence of this second term, ends up destroying the linearity of the growth law ([62], p. 128).

The nonlinear differential Logistic Equation (6) (differential Logistic model in continuous times) has exact solutions, whose trajectory or time trend is a S-shaped curve. The population asymptotically (that is, in the limit) approaches the straight line (the carrying capacity), either increasing or decreasing toward it, depending on the initial population $\mathrm{y}_{0}$. The period of time before the population reaches half its limiting value is a period of accelerated growth and the solution curve rapidly increases. After this point, the rate of growth decreases and in the long run reaches zero. This is a period of diminishing growth and the solution curve gradually decelerates until it stabilizes (derivative set at zero). As it is known, analytically the exact solution is obtained by the following equation:

$$
y(t)=\frac{a y_{0}}{b y_{0}+\left(a-b y_{0}\right) \mathrm{e}^{-a\left(t-t_{0}\right)}} .
$$

In the discrete case, if in Equation (7) we divide by $\frac{a}{b}$ —maximum level of sustainability-and, therefore, if we let $x_{t}=\frac{y_{t}}{\frac{a}{b}}$ or $x_{t}=\frac{b}{a} y_{t}$, the $y$ variable is transformed into the $x$ variable ( $x$ values from 0 to 1$)$, and we obtain the following difference logistic equation

$$
\begin{gathered}
x_{t+1}-x_{t}=a x_{t}-b x_{t}^{2} \quad(\Delta t=1,0<x<1) \\
x_{t+1}-x_{t}=a x_{t}\left(1-\frac{b}{a} x_{t}\right)
\end{gathered}
$$

and consequently its solution is:

$$
x_{t+1}=x_{t}+a x_{t}\left(1-\frac{b}{a} x_{t}\right)
$$

Through several complex mathematical steps, it assumes the simplified structure of the Logistic map (discrete Logistic equation) ([62], p. 215). Indeed, if we let 


$$
\begin{aligned}
& \frac{b}{a} x_{t}=\frac{x_{t}}{\frac{a}{b}} \text { and } \frac{a}{b}=k \text {, we obtain } \\
& \\
& x_{t+1}=x_{t}+a x_{t}\left(1-\frac{x_{t}}{k}\right) \\
& x_{t+1}=x_{t}+a x_{t}\left(k-x_{t}\right) .
\end{aligned}
$$

If we indicate the maximum limit $k$ as $L k$, the Equation (10.2) it can be rewritten as:

$$
x_{t+1}=x_{t}+a x_{t}\left(\mathrm{~L} k-x_{t}\right)
$$

whose derivative equation

$$
x_{t+1}-x_{t}=a x_{t}\left(\mathrm{~L} k-x_{t}\right)
$$

is equivalent to Equation (9.2).

By Equation (10.3), if we let $x_{t}=\frac{k(1+a)}{a} x_{t}$, we obtain

$$
\frac{k(1+a)}{a} x_{t+1}=\frac{k(1+a)}{a} x_{t}+a * \frac{k(1+a)}{a} x_{t} *\left(1-\frac{\frac{k(1+a)}{a}}{k} x_{t}\right)
$$

and simplifying

$$
\frac{k(1+a)}{a} X_{t+1}=\frac{k(1+a)}{a} X_{t}+k(1+a) X_{t}\left(1-\frac{1+a}{a} X_{t}\right)
$$

If we multiply the Equation (11.2) by $\frac{a}{k(1+a)}$, the equation becomes

$$
\begin{aligned}
& x_{t+1}=x_{t}+a x_{t}\left(1-\frac{1+a}{a} x_{t}\right) \\
& x_{t+1}=x_{t}+a x_{t}-(1+a) x_{t}^{2} \\
& x_{t+1}=(1+a) x_{t}-(1+a) x_{t}^{2} .
\end{aligned}
$$

Finally, if we let

$$
\lambda=(1+a)
$$

we obtain the standard form of the Logistic map, which in discrete time with $\Delta t=1$ is the solution of differential Equation (9.2):

$$
x_{t+1}=\lambda x_{t}-\lambda x_{t}^{2} \quad(\Delta t=1)
$$

or else

$$
x_{t+1}=\lambda x_{t}\left(1-x_{t}\right) .
$$

Usually the notation $\lambda$ is replaced by $k$. The Logistic map, $x_{t+1}=k x_{t}\left(1-x_{t}\right)$, is the simplest nonlinear equation (of course, the nonlinearity regards the parameters). As well as in the continuous time equation, it is a quadratic map whose solution cannot generally be found using algebra but by numerical iteration. In more detail, the equation indicates that $x_{t+1}$ is a Non-Linear function of $x_{t}\left(x_{t+1}=f\left(x_{t}\right)\right)$. Analyzing in detail the discrete equation, the formula tells us that the consistency of the $x$ variable in $t+1$ time, for example, of a biological population, or an organizational population (social groups like bureaucratic, political, industrial apparatus and so on) depends on the consistency of the variable over time $t$, according to a $k$ growth parameter. This parameter is not 
constant as it would be if the growth were linear, because the environment cannot support unlimited growth. As we previously said, a certain population can reach a maximum number of individuals, according to the limited natural resources available. Thus, the more the population reaches its carrying capacity (maximum level of sustainability), the more the environment will discourage further growth. In other words, when population reaches the carrying capacity its growth is zero. This, however, it is not enough: the carrying capacity has to show its influence even before that population reaches its possible maximum, that is, it has to show its influence by restraining the speed or population growth rate in a degree, as greater as $x$ increases. So, the Non-Linear $1-x_{t}$ component expresses the restraint that the environment poses on the $x$ variable increase. The reasoning behind this is rather simple. In $1-x_{t}, 1$ stands for $100 \%$ environment carrying capacity, its theoretical limit of sustainability. Thus, if $x_{t}$ were $1 \%$ there would be $99 \%$ resources left to sustain greater population increase (1 - 0.01$)$, and $99 \%$ multiplied by $k$ (and then $x_{t}$ ) can hardly lower the growth rate (if $k$ were 2 , the growth rate would be $99 \%$ of 2 , or $1.98 x_{t}$ ). On the contrary, if the population is $80 \%$ of the maximum value sustainable by the environment, there will be few resources to sustain further growth or rather $20 \%(1-0.80)$. The growth rate would be reduced by environment pressure (a $20 \%$ of 2 reduction or $0.4 x_{t}$ ) and thus further growth would be discouraged. The population falls; hence, with low population values, growth still continues but at an ever decreasing rate, until in time, being growth rate, lower and lower, $x_{t}$ stabilizes at a fixed value (if $k=2, x_{t}$ stabilizes at 0.50) [63].

As observed by Marion, the whole question makes perfect logical sense, as well as naturally, mathematical sense ([63], p. 201).

The transformation from Equation (7) to Equation (9.1) is useful just because it "normalizes" the $y$ variable between 0 , the minimum value, and 1 , the maximum value. This is particularly useful for the study of the model. It can be solved without considering the particular value of carrying capacity and simply expressing the population in percentage terms compared to the maximum allowed. This transformation imposes some constraints on $k$ values: $k$ cannot be negative (so that population does not become negative) and cannot exceed 4 (so that population does not exceed 1 , which is the maximum allowed).

To find the equilibrium points of the equation we let $f\left(x^{*}\right)=k x^{*}\left(1-x^{*}\right)=x^{*}$. Thus, we pinpoint two equilibrium points ([64], p. 17):

$$
x^{*}=0 \text { and } x^{*}=\frac{k-1}{k} \text { or } 1-\frac{1}{k} .
$$

The value of the Logistic approach becomes clear when one considers the type of additional information it provides compared to traditional statistical approaches. Experts were fascinated by the surprisingly complex behaviour by that which is the most simple of discrete Non-Linear one-dimensional systems. A bizarre behaviour, said May [50]. In effect, in spite of its simplicity, it exhibits a rather rich and complicated dynamics: the equation can describe a behaviour that culminates at an equilibrium point, the so called steady state, or it can describe a periodic behaviour with ever increasing cycle lengths, or it can have what seems to be totally random fluctuations. It is, however, basically important to note that such dynamical behaviour depends exclusively on the $k$ parameter value. The value of $k$ describes the whole of "characteristics of the system" which cause that system to be either stable, oscillating in a complex manner, or chaotic. More specifically, when the value of $k$ is between 0 and 3, the system stabilizes at a fixed point, the so called steady state or point of equilibrium, representing system's attractor ${ }^{3}$. The graph of $x_{t}$ values versus t shows a sequence of values that approache a certain

\footnotetext{
${ }^{3}$ Attractors are geometric structures described by the system in its evolution. These geometric shapes attract all the orbits starting from different initial conditions, hence the name attractors. These shapes can be discovered by using state space or phase space mapping. A phase space represents a graphic backdrop for presenting the motion of time-based data. We construct a XY graph and place on the horizontal axis or abscissa the observed values $x_{t}$ and on the vertical axis or ordinates the same values measured with time delays or $x_{t-n}$ delayed by 1 , 2, 3, and so on, time lags. The most suitable time lag for reconstructing the attractor, found by experiments, usually, however, it is set at equal 1. The values $x_{t}$ and $x_{t-n}$ constitute the coordinates of a point on a multidimensional space, and the set of points identified in this way describe an orbit which in the long run, traces the typical attractor of the observed system. In fact, according to Takens theorem the geometric shape thereby constructed is topologically equivalent to the original attractor, that is the one that would be reconstructed if we knew exactly the number and the values of variables explaining the observed dynamical process (or if we knew the governing equation of motion of the nonlinear system). In fact, it maintains the properties of the original attractor, including the dimension. This topological equivalence is called by a complicated term diffeomorphism.

Every system has its own attractor, with its typical shape. For example, if a system is stable, (forced pendulum), the attractor is at a fixed point. If the system displays periodic behavior the attractor is a limit cycle (free pendulum). When the system is chaotic, the attractor assumes the strangest shapes, thus the attractor is called strange. In the case of logistic equations, the system's attractor is reconstructed considering a bi-dimensional space $x_{t} / x_{t-1}$. Setting the $x_{t}$ values on the abscissa and $x_{t-1}$ values on the ordinate, the points that are identified by the coordinates $x_{t}$ and $x_{t-1}$ form a hill-shaped attractor.
} 
state and remain fixed there. As we said, for example, if $k=2 x$ variable reaches a balance between growth pressure and environmental constraints at $\frac{k-1}{k}=0.50$ [63]. According to $k$ value, all orbits (the succession of value $x_{0}, x_{1}, x_{2}, \cdots$ starting from a specific value of $x_{0}$ ), no matter the value of initial condition $x_{0}$, tend to the same stable fixed point as $t \rightarrow \infty$. In our example, all orbits, no matter where started, tend to the same stable fixed point of $x=0.50$ as $t \rightarrow \infty$. If growth rate $k$ is less than 1 , the population will get smaller until eventually it is infinitesimally small—for all practical purposes it ceases to exist. As $k$ increases, system behaviour becomes more and more complicated. The stationary state loses stability as soon as $k$ is more than 3 : the system begins to fluctuate, becomes unstable but is able to evolve, reorganizing itself around a new configuration. So at 3.2 bifurcates, splitting up, dividing into two new fixed points. The system alternates between these two fixed points in a stable 2 period cycle. Obviously, given the two values which repeat sequentially, the model tells us that the $x$ variable possesses a biennial, bi-semestral, bi-monthly, bi-weekly, ... cyclical variation, according to time unit used.

Once again, cycle stability remains until the parameter passes a certain critical threshold: beyond this point, the system becomes unstable and the process "bifurcates" creating a new cycle. It, initially stable, has a newdoubled-period. In fact, another interesting bifurcation (system change point) is created around a $k$ value of 3.5. The cycle time doubles to 4 , so that now there are 4 values that alternate. In other words, 4 years, 4 months, or 4 days must pass in order to return to the initial value and to repeat the sequence. The period doubles for $k=3.56$, passing to a recursive sequence composed by eight values, and goes on and on this way till $k$ keeps on increasing, creating bifurcation upon bifurcation, up to $16,32,64,128$, etc. cycle times. Naturally, the various cycles to which the process tends are the system's attractors.

In technical terms, what we are viewing is a real period-doubling cascade, or rather an infinite cycle sequence of period $2^{\mathrm{n}}$. And it is exactly "this truly fantastic bifurcation phenomenon", as Smale and Williams defined it, which is widely acknowledged as the road to chaos [65]. In fact, when $k$ is in the range of 3.8 to 4 , the system's behaviour enters into a regime that $\mathrm{Li}$ and Yorke first named 'chaotic' [66]. Values are erratic, a-periodic, without ever repeating themselves, and therefore, appear to have no rules. The graph of the solutions of the nonlinear equation versus $t$ shows that $x_{t}$ values exhibit a random trend. But randomness is merely apparent, since the nature of the mechanism or equation governing behaviour is still deterministic. Hence the same mathematical model (the same equation) allows predictable behaviour in some regions of model parameters, and unpredictable behaviour in others. A chaotic change of $x$ expresses an unpredictable asset of interactions among elements of the system (deviants, consumers social and political agents, atoms, ecological populations, etc.). As an example, if Logistic mapping is used for modelling electoral volatility, a chaotic behaviour in the level of electoral support (number of votes) of a party expresses underlying disordered, instable, unpredictable political decision-making processes. Of course, this leads us to reflect upon the factors encouraging the predictability breakdown in the structure of political and social relationships [16].

Chaotic behaviour is the most interesting behaviour which a simple, deterministic model such as the Logistic map can exhibit. This is synthesized in the concept of deterministic chaos, expressing the new scientific idea according to which order and disorder are no longer opposing categories: disorder can come from order. This new acknowledgment — this is the very interesting aspect—led us to bridge the gap between scientific determinism and probabilism [24].

The dynamic behavior deriving from the logistic equation, depending on the $k$ value finds a good graphic portrayal in this well-known bifurcation diagram. In Figure 1, we see clearly the system's bifurcation points or the values of unstable equilibrium — placed on the ordinate - that $x$ exhibits as a function of $k$ value — placed on the abscissa.

We might say that $k$ represents a sort of "regulating device", when we turn it on we get a constant rise in dynamic behavior complexity: stationary $\rightarrow$ periodic $\rightarrow$ chaotic, with period doubling cascade as the mechanism generating chaos [24].

Therefore, it can be concluded that every phenomenon whose process is modeled by the logistic equation expresses an underlying deterministic nature, which is responsible for every bounded evolution change including any eventual erratic behavior. In other words, phenomena hide an underlying order which has its own formal and geometric "physiognomy". As a rule, in the case of chaotic behavior, the underlying order takes on a bellshaped attractor.

The discovery of its regularity in the Social Sciences has relevant consequences. We can say that the Logistic map is the structure of a Non-Linearly oriented social phenomenon. We can consider social phenomena as not 


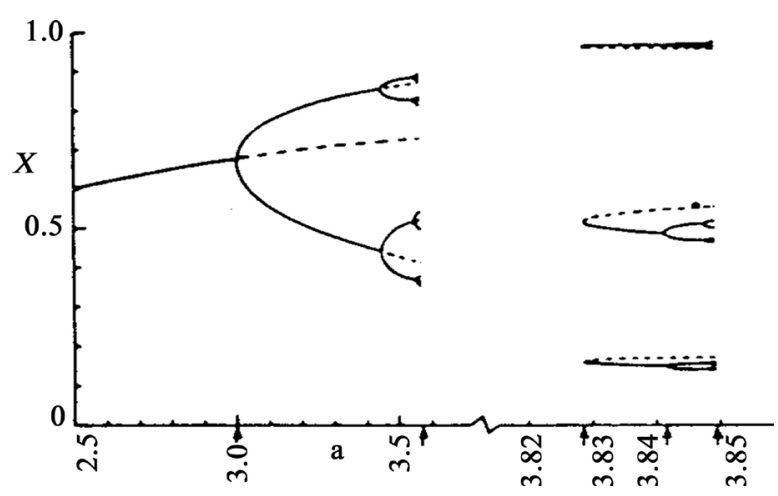

Figure 1. Stylization of bifurcation diagram or Feigenbaum's tree $(0 \leq \mathrm{x} \leq 1,0 \leq \mathrm{k} \leq 4)$.

being susceptible to unlimited growth but rather bounded in their development. In short, factors which contribute to the growth and factors whose action reduces their growth rate, taken collectively, provide the limits of a bounded social system, thereby preventing an exponential increase. The $k$-value in social system provides important information about social intervention and control processes. Low $k$-values suggest a process far from a chaotic behavior, being able either to increase or decrease depending upon the current state of the system. When system's behaviour flows into a chaotic behaviour every predictability and control capacity is lost.

\subsection{Implications of Complexity and Chaos Theory in Social Science Research}

The success of the Logistic map demonstrates how we can study social phenomena discontinuity scientifically, avoiding a purely metaphorical use of the complexity and chaos approach. The logistic equation allows us to pass from theory to practice and to revise traditional approaches marked by a linear deterministic view implying predictability and control of social phenomena and therefore unsatisfactory analytical outcomes. The heuristic importance of a nonlinear analytical approach now seems evident. In light of this, we want re-emphasize the two main implications regarding Complexity and Chaos Theory for social science research.

As already noted, the new science loosens the ties between determinism and predictability, supported by Laplace's theory and discovers that absolutely unpredictable dynamic behaviours are produced by deterministic laws or, in other words, that disorder can arise from order.

The first implication of this new acquisition for scientific research and for social science research in particular is clear. Complex and chaotic systems can be understood, even if not predicted. On one hand, research has to reassess its ambitions regarding predictability, yet it can and must focus on discovering mechanisms and laws which structure and generate discontinuity (basic equations governing systems' behavior). Knowing the laws or the Non-Linear basic equations of motion allows us to have a better understanding of social systems. As we have previously said, Brown illustrates these course changes from a linear standpoint in the following metaphor:

Social phenomena are like serpents. Not much is linear about them, particularly with regard to their movements through time. They follow not a direct path, but wind among the vagaries of the development of the broader human culture. This broader culture also is not fixed. It is like sand. The marks that are made on it by social phenomena quickly blend into the historical evolution of this culture, mixing with the previous marks of all other phenomena, until it is difficult to say that any one mark is distinct from all of the others. We live in a human universe of movement and change. That which seems fixed may be only the ghost of a contrived static perspective that ignores the continuing evolution of human interdependencies. [...] most of our experiences are those of change within a background of further change; our lives developing like the movements of serpents, serpents in the sand" ([10], p. 10).

This consideration introduces us to the second implication.

As noted, Complexity and Chaos Theory introduces a different way of thinking about predictability. Is it really possible to consider non-predictability and hence un-controllability of social phenomena devoid of any heuristic value? From a sociological point of view we can give a firm negative answer. It is significant to know whether a phenomena presents chaotic behavior and therefore cannot be controlled, or to know that it is on the edge of chaos, i.e. in a transition zone, approaching chaos, thus on the verge of not being controllable. 
Let us note, that certain modern perspectives seem to revolve around this latter scenario. For instance, during the last decades, we have seen the trend of defining some phenomena like wars, in terms of loss of control more than in the usual terms of the past such as "the will to go to war" or "conspiracy" and so on. Saperstein's view is opportune in this regard.

I suggest that war be viewed as a breakdown in predictability: a situation in which small perturbations of initial conditions, such as malfunctions of early-warning radar systems or irrational acts of individuals disobeying orders, lead to large unforeseen changes in the solution to the dynamical equations of model. There is no way then to predict the effect of the actions of any participant-analyst, planner, statesman or General - with any certainty. Certainly war, between roughly equivalent parties, has often been characterized by uncertainty in outcome; nations which start wars in great confidence very often end defeated. Typically, in the period immediately before the outbreak of a war the nations attempt desperately to claw back as they slide over the precipice, although they, by this time already have lost control of their own destinies: control and predictability are lost” ([40], p. 303).

Historians, on their part, seem to support this view. For example, the problem of ascertaining what the causes of the outbreak of the Great War were, is still an open issue. Recently, documents have been exhibited where scientists are led to believe that Hitler was a long way from wanting to start a world-wide conflict so soon, and without delay. This perspective has ethical and political implications as well. For example, a politician passes certain legislation concerning a social phenomenon, which was ascertained to have chaotic behavior. The politician would be obliged to admit to an adequately informed public opinion that the new bill might have consequences that no one is able to predict.

To sum up, non-predictability and uncontrollability cannot be considered of little interest and consequentially knowing the threshold where phenomena turns into chaos is precious information, in attempting to prevent and therefore to avert reaching an uncontrollable situation.

We previously said that even if we are unable to predict future outcomes in a phenomenon's dynamic evolution (of a biological population, of a social or electoral competition, of industrial production, of spread of disease or of a technological invention), Non-Linear dynamics study through building nonlinear models allow us to "predict" what conditions (parameter values) give way to certain types of dynamic behavior. We are able to know at what values a company goes bankrupt, a party loses the elections, a political system become instable, a war breaks out, crime waves become uncontrolled and social control systems disorganize. In the same way, we are able to know at what values a biological population (as well as a disease) dies out or evolves into a periodic or chaotic behaviour. This type of knowledge is much more important for intervention policies (social or otherwise) than an exact knowledge of the system's future evolution outcomes.

For further clarification of this point, let us apply this argument to a social phenomenon like noncompliance-coercion relationships already quoted above, where the relationship is modeled according to a logistic structure. The study of this model tells us that at $k$ values under 3, 8-4 crime variability remains in a situation of possible controllability. In this situation any intervention aimed at influencing the system's current trend (in this specific case, assure a decrease in crime) can produce expected outcomes. Obviously, we need to avoid the situation from falling into a chaotic range and it is always the model which indicates that this can happen if the $k$ value reaches $3,8.4$. This value marks an alarming loss in predictability and therefore in control. It would be impossible, in fact, to predict what would happen in this case. Note, we are not saying that we would not know what to do in such a situation - or what line of intervention to take. We are saying something much different, namely that social phenomenon flowing into chaos produces absolutely unpredictable outcomes for any intervention adopted. It has been shown that if the crime rate reached this value, flowing into chaos, it would pull law enforcement agencies into chaos as well. In conclusion, the galloping, uncontrollable rise in crime would disorganize any form of intervention able to adapt the police force and their work to such an uncontrollable increase in crime For instance, a law enforcement agency may increase the number of police officers but we have no idea what the outcome will be. Thus, measures taken to reduce crime might have a completely opposite outcome; they may produce even a further rise in crime rates or an actual fall in these rates. The problem is that we are unable to predict what outcome will emerge. Priesmayer provides us with an exemplifying case, regarding cocaine use in the USA from 1985 to 1990. In his investigation, the logistic equation fits cocaine use with a value $k$ of 3.6, dangerously close to the critical threshold of 3.8, a value inducing the author to the following disarming conclusion: 
Put simply, actions which decrease current use may contribute to higher future use or they may not; actions which contribute to higher current use may contribute to lowering use in the future or they may not [...]. Does it suggest that $[. .$.$] attempts to lower cocaine use by aggressive intervention are far less certain? If$ cocaine use is not controllable in this way, what then is to be used to control cocaine use? ([43], p. 333).

In brief, no one is able to define the terms of a scenario. Or rather, any type of scenario is equally possible. Possible scenarios might mirror films such as Escape from New York or, on the contrary, film series where enforcement agencies become powerful managers of criminal enterprises. In an extreme case (not so extreme if we judge by current situations), crime agencies and police could form alliances creating strange symbiotic phenomena. This idea is suggested by the situation in Russia, where events appeared dangerously on the edge of chaos or pre-chaos. The rise in the crime rate led to a rise in police enforcement, yet the reduction of crime was not forthcoming. In fact, there was more and better orchestrated collusion and corruption between law enforcement and criminal enterprises. In this scenario, it is not rhetorical to ask where crime control efforts will end up and what line of action will be taken against noncompliance.

To avoid similar dangers, I repeat, it is absolutely important to know and therefore to be able to predict the threshold of chaotic behavior for a social science researcher. Consequently, the study of models of nonlinear dynamical systems suitable for attaining this knowledge is also of prime importance.

Referring back again to Saperstein, for example, by using a simple bilateral logistic model, the author estimated that it would be sufficient to have a parameter over 1, in one of its equations for a transition into chaos or, in other words, the break out of war. It is evident that this knowledge can give a significant contribution to any peace oriented policy, by controlling that the arms build-up stays below the critical threshold level. Saperstein did not only limit himself to a 'theoretical' study, but provided empirical examples. He analyzed the arms race of different couples of European nations during 1936-37, and between the USA and the URSS in the $70 \mathrm{~s}$ and 80 s. It was ascertained that the relationship between Nazi Germany and the Soviet Union were within "a chaotic region" ( $a=1.34, b=0.0657)$ : in fact, this case history has shown us the intrinsic uncertainty connected to a state of war. In USA and URSS relations, the chaotic region was instead only touched [40].

Brown successfully uses nonlinear modeling in order to analyze the destabilization process of the Weimar Republic and the rise of the Nazi party in a fragmented and very unstable political ecosystem [10]. Gottman et al.'s study on marital relations is also relevant. It presents these relationships as a discontinuous process (both stable and prone to catastrophe), and analyzes this discontinuity applying a nonlinear model using difference equations. The model indicates the threshold beyond which a marriage is expected to break up [48].

To conclude, from a heuristic point of view, there is more than one valid reason to support the use of Non-Linear instruments in social system analysis.

\section{Conclusions}

To conclude, Complexity is neither a fad or a whim, nor today's mania. We cannot but admit how constructive this contribution of Complexity and Chaos is, in regards to the conception of systems, of their working and change mechanism, of the relationship between system and environment and between micro and macro levels of analysis, and of the long lasting problem of the relationship between order and disorder in natural and Social Sciences. Today, the terms of the redefinition of relationships between order and disorder are the basis of contemporary scientific thought, in its new configuration of linking inter-relationships, according to a unicum which finds its synthesis in weak determinism, in self-organization and in deterministic chaos concepts. From this perspective, Complexity Theory has contributed in re-addressing fundamental issues for Sociology as well, starting to social system concept. Far from equilibrium self-organising, emergence, surprise, and self-reproduction concepts have contributed to a new way of thinking, today, about social systems in Sociology.

The study of Complexity is endowed with great heuristic value. By detecting the rule in discontinuity, surprise and uncertainty, it allows us to be brought out of the limbo of brain teaser social discontinuity (market and international political competitions instability, electoral volatility, social control processes, spread of social epidemic), just as the Natural Sciences have brought out of the limbo of the brain teaser natural discontinuity such as atmospheric and fluid turbulence [13]-[67]. We now have much strong evidence that this new approach represents an objective qualitative leap, allowing satisfactory solutions to problems that hitherto, being treated by other logic, had been left substantially open and stored away, destined to remain open cases forever.

Although the Complexity approach is drawing up a theoretical framework, which allows us to describe and 
understand the behavior of natural and social systems more realistically than before, this framework has not yet reached that degree of unity to be able to talk about one unique Complexity Theory. This last point is still the subject of ongoing reflection.

In addition to the issue of predictability, which was addressed in the paragraphs above, the ability to construct a unified theory of complex systems that applies to physical, chemical, biological, immune, neurological, weather, population, economic, and political systems is, in fact, a highly debated question.

Complexity researchers such as Bak [68], Holland [69], Langton [70] and Kauffman [3] support this latter possibility. Holland, for example, has insisted on a unified theory of Complex Adaptive Systems based on mathematical techniques such as those used in his genetic algorithms. The same can be said for Bak, who considers self-organized criticality as the common mechanism at the basis of all complexity systems (Geological, Biological, and Socio-Economical) and therefore the foundation of a unified theory of complex systems.

On the contrary, other researchers deny this possibility. Some have insisted on the fact that, in reality, the power law, on which the theory of self-organized criticality is based, has not shown the degree of generality desired by Bak. Some other authors even doubt that science can achieve a unified theory of complex systems able to go beyond some general principles, considering it a reductio ad absurdum.

According to Anderson [71], for example, reality has a hierarchical structure, where each level is in some degree independent and separate from the one above and below it. In this regard, "Psychology is not applied Biology and Biology is not applied Chemistry” ([71], p. 393). This means that a good general principle at a given level does not imply that it will necessarily apply to all the levels, but at every level we need completely new laws, ideas and generalizations.

If, according to Anderson, it is impossible to go up the chain of explanations from Particle Physics to Biology, Gell-Mann [72] supports this possibility in principle. The difficulty in applying it, is just a matter of practice for Gell-Mann, because biological phenomena are generated by too many random, historical and contingent circumstances. Therefore, Gell-Mann excludes the fact that we are governed by exclusive natural laws or yet undiscovered laws, which work independently from the basic laws of Physics. Unlike Kauffman and Bak’s view, though still within the reductionist position, the complexity of life, of human existence and of man's consciousness all comes from fundamental Physical laws.

This question still remains an open issue. Nevertheless, there is no denying that the identification of non linearity in the interaction between the elements of a system, as cause of complexity, is a factor uniting the Dissipative Structures Theory, the Theory of Adaptive Systems, and the Autopoiesis Theory, and, as a result, a vast variety of systems. For that matter, this is the meaning of the New Alliance that Prigogine has handed down to us.

The meaning of the New Alliance [6] does not allude to the acquisition of a unified theory encompassing Politics, Economy, immune systems, Physics and Chemistry. But, if it is true that progress in the field of chemical reactions far-from-entropy (equilibrium) cannot provide us with the key for the study of Politics, research on Dissipative Systems has introduced a unifying component, having shown that ideas such as self-organization, bifurcation, irreversibility, evolution, historical dimension, emergence and surprise meet at all levels and provide the basis for a new way of thinking about systems in sociology as well as other disciplines. The New Alliance actually alludes to the bridge that the new science has built between the Natural Sciences, which have always described nature as a result of classic science deterministic laws, and humanistic disciplines, tending to underline man's freedom and the emergent, surprising historicity of its social realizations, thus ensuring the celebration of nature's re-enchantment. On this latter point, we might perhaps object to Prigogine, as does Horgan [73], that it is not easy to understand in what way the vision of an unpredictable, uncertain, even if re-enchanted, world is more comforting than the scientific vision of a predictable, timeless, deterministic world, However, if we separate judgments of fact from value judgments, the sense of the new alliance goes much deeper. On the level of judgment of fact, it defines the foundation of a new way of looking at and knowing the world, in light of criteria that constitutes a unifying element of our conception of the universe, even beyond its recognized systemic diversity.

In conclusion, there is no denying that the major scientific discoveries of this century have established the

\footnotetext{
${ }^{4}$ According to Gell-Mann, there is no need for new laws to explain why the universe has generated so much order despite the universal drift to create disorder, sanctioned by the second law of thermodynamics. Simply put, the universe most likely began in a state of maximum tension, far-from-entropy or thermal equilibrium. On one hand, entropy increases on average in the entire system, on the other hand, this tendency can break down at local levels.
} 
limits of science with its Newtonian and probabilistic descriptions. And, inevitably, complexity challenges us about the nature of reality. It raises questions that cannot be liquidated merely by thinking that acquisition of concepts such as emergence, surprise, and unpredictability are really sic et simpliceter only alibis to hide our scientific failures behind. Dissipative structures have shown the creative role of time, and how instability, emergence, surprise and unpredictability are the rule and not the exception when we move away from equilibrium (entropy). As Prigogine observes, studies that deal with dissipative structure discoveries and ideas that revolve around irreversibility, self-organization and emergence the link between order and disorder, in short, around the complexity of systems, are strongly heading toward a historical, biological conception of Physics (see also [74]). This means translating the affinity between concepts of self-organization and evolution into evolutionary Darwinian terms, where mutations correspond to fluctuations, and selection corresponds to search of stability and self organization production whose outcome is not given, but where unpredictability appears to be intrinsic to systems even if they are deterministic systems, in a new alliance between natural systems and living, social systems. Thus, complexity poses a challenge for future research, projecting it in completely new theoretical and methodological areas. Today, it has to be focused on the game rules that allow us to understand the interplay between order and disorder, or, to put it in sociological terms, between realism and postmodernism, so we can feel, by paraphrasing Kauffman, at home in the universe.

\section{References}

[1] Lewin, R. (1992) Complexity. Life at the Edge of Chaos. Mcmillan, New York.

[2] Waldrop, M. (1992) Complexity: The Emerging Science at the Edge of Order and Chaos. Simon \& Schuster, New York.

[3] Kauffman, S. (1995) At Home in the Universe: The Search for Laws of Self-Organization and Complexity. Oxford University Press, Oxford.

[4] Holland, J.H. (1998) Emergence: From Chaos to Order. Addison-Wesley, Reading.

[5] McDaniel, R.R. and Driebe, D.J. (2010) Uncertainty and Surprise: An Introduction. In: McDaniel, R.R. and Driebe, D.J., Eds., Uncertainty and Surprise in Complex Systems, Springer, New York, 3-11.

[6] Prigogine, I. and Stengers, I. (1979) La Nouvelle Alliance. Metamorphose de la science. Gallimard, Paris

[7] Maturana, H. and Varala, F. (1984) El arbol del conocimiento. Editorial Universitaria, Santiago.

[8] Harvey, D.L. and Reed, M. (1997) Social Sciences as the Study of Complex Systems. In: Kiel, D.L. and Elliott, E., Eds., Chaos Theory in the Social Science: Foundations and Applications, the University of Michigan Press, Ann Arbor, 295-323.

[9] Crutchfield, J., Farmer, J.D., Packard, N.H. and Shaw, R.S. (1986) Chaos. Scientific American, 255, 46-57. http://dx.doi.org/10.1038/scientificamerican1286-46

[10] Brown, C. (1995) Serpents in the Sand. Essays in the Nonlinear Nature of Politics and Human Destiny. The University of Michigan Press, Ann Arbor. http://dx.doi.org/10.3998/mpub.23262

[11] Poincarè, H. (1908) Science et méthode. Ernest Flammarion, Paris.

[12] Ruelle, D. (1991) Chance and Chaos. Princeton University Press, Upper Saddle River.

[13] Gleick, J. (1987) Chaos: Making a New Science. Viking Penguin Inc., New York.

[14] Denhardt, R. (1993) Theories of Public Organization. Wadsworth, Belmont.

[15] Elliott, E. and Kiel, D.L. (1997) Nonlinear Dynamics, Complexity, and Public Policy. Use, Misuse, and Applicability. In: Eve, R.A., Horsfall, S. and Lee, M.E., Eds., Chaos, Complexity, and Sociology, Myths, Models and Theories, Sage Publications Inc., Thousand Oaks, 64-78.

[16] Brown, C. (1991) Ballots of Tumult. A Portrait of Volatility in American Voting. The University of Michigan Press, Ann Arbor. http://dx.doi.org/10.3998/mpub.23411

[17] Prigogine, I. (1997) The End of Certainty. The Free Press, New York.

[18] Ceruti, M. (2007) La hybris dell’onniscienza e la sfida della complessità. In: Bocchi, G. and Ceruti, M., Eds., La sfida della complessità, Mondadori, Milano, 1-24.

[19] Prigogine, I. (2010) Surprises in a Half Century. In: McDaniel, R.R. and Driebe, D.J., Eds., Uncertainty and Surprise in Complex Systems, Springer, New York, 13-16.

[20] Elliott, E. and Kiel, D.L. (1997) Introduction. In: Kiel, D.L. and Elliott, E., Eds., Chaos Theory in the Social Science: Foundations and Applications, the University of Michigan Press, Ann Arbor, 1-15. 
http://dx.doi.org/10.1017/cbo9780511983405.003

[21] Lorenz, E.N. (1963) Deterministic Nonperiodic Flows. Journal of Atmospheric Science, 29, 130-141. http://dx.doi.org/10.1175/1520-0469(1963)020<0130:DNF>2.0.CO;2

[22] Morin, E. (1990) Introduction à la pensèe complexe. Edition du Seuil, Paris.

[23] Einstein, A., Born, M. and Born, H. (1981) Scienza e Vita. Lettere 1926-1955 (Scattone, G., Translate It). Einaudi, Torino.

[24] Stewart, I. (1989) Does God Play Dice? The Mathematics of Chaos. Blackwell, Cambridge.

[25] Bailey, K. (1984) Beyond Functionalism: Toward a Nonequilibrium Analysis of Complex Social Systems. British Journal of Sociology, 35, 1-18. http://dx.doi.org/10.2307/590548

[26] Parsons, T. and Shils, E.A. (1951) Toward a General Theory of Action. Harper \& Row, New York. http://dx.doi.org/10.4159/harvard.9780674863507

[27] Von Bertalanffy, L. (1969) General System Theory. Braziller, New York.

[28] Prigogine, I. (1980) From Being to Becoming. Time and Complexity in the Physical Sciences. W.H. Freeman and Company, San Francisco.

[29] Prigogine, I. and Stengers, I. (1984) Order out of Chaos: Man's New Dialogue with Nature. Flamingo Edition, London.

[30] Ball, P. (2012) Why Society Is a Complex Matter. Springer, New York. http://dx.doi.org/10.1007/978-3-642-29000-8

[31] Miller, J.H. and Page, S.E. (2007) Complex Adaptive Systems. An Introduction to Computational Models of Social Life. Princeton University Press, Princeton.

[32] Bailey, K. (1994) Sociology and the New Systems Theory. Toward a Theoretical Synthesis. State University of New York Press, New York.

[33] Luhmann, N. (1984) Soziale Systeme. Suhrlamp, Frankfurt am Main.

[34] Luhmann, N. (1986) The Autopoiesis of Social Systems. In: Geyger, F. and van der Zowen, J., Eds., Sociocybernetics Paradoxe, Sage, London, 174-192.

[35] Archer, M.S. (1995) Realist Social Theory: The Morphogenetic Approach. Cambridge University Press, Cambridge. http://dx.doi.org/10.1017/CBO9780511557675

[36] Sawyer, R.K. (2005) Social Emergence. Societies as Complex Systems. Cambridge University Press, Cambridge. http://dx.doi.org/10.1017/CBO9780511734892

[37] Byrne, D. and Callaghan, G. (2014) Complexity Theory and the Social Sciences: The State of the Art. Routledge, London.

[38] Reed, M. and Harvey, D.L. (1992) The New Science and the Old: Complexity and Realism in the Social Sciences. Journal for the Theory of Social Behaviour, 22, 353-380. http://dx.doi.org/10.1111/j.1468-5914.1992.tb00224.x

[39] Huckfeldt, R. (1990) Structure, Indeterminacy and Chaos. A Case for Sociological Law. Journal of Theoretical Politics, 2, 413-433. http://dx.doi.org/10.1177/0951692890002004004

[40] Saperstein, A.M. (1984) Chaos—A Model toward for the Outbreak of War. Nature, 309, 303-305. http://dx.doi.org/10.1038/309303a0

[41] Tsebelis, G. and Sprague, J. (2010) Coercion and Revolution: Variations on a Predator-Prey Model and Computer Disorder? Criminology and Public Policy, 9, 139-173.

[42] Huckfeldt, R. (1989) Noncompliance and the Limits of Coercion: The Problematic Enforcement of Unpopular Laws. Mathematical and Computer Modelling, 12, 533-546. http://dx.doi.org/10.1016/0895-7177(89)90423-8

[43] Priesmeyer, R.H. (1995) Logistic Regression: A Method for Describing, Interpreting, and Forecasting Social Phenomenon with Nonlinear Equations. In: Albert A., Ed., Chaos and Society, IOS Press, Amsterdam, 329-338.

[44] Dendrinos, D. (1992) The Dynamics of Cities. Routledge, London. http://dx.doi.org/10.4324/9780203417690

[45] Dooley, K., Hamilton, P., Cherri, M., West, B. and Fisher, P. (1997) Chaotic Behavior in Society. Adolescent Childbearing in Texas, 1964-1990. In: Eve, R.A., Horsfall, S. and Lee, M.E., Eds., Chaos, Complexity, and Sociology, Myths, Models and Theories, Sage Publications Inc., Thousand Oaks, 102-122.

[46] Condorelli, R. (2013) Applied Nonlinear Dynamical System in Social Science. A Nonlinear Model for Social Control System: An Application to Italian Coercion System. Quality \& Quantity, 47, 1173-1198. http://dx.doi.org/10.1007/s11135-012-9666-7

[47] Condorelli, R. (2016) Social Complexity, Modernity and Suicide: An Assessment of Durkheim's Suicide from the Perspective of a Non-Linear Analysis of Complex Social Systems. SpringerPlus, 5, 374.

http://dx.doi.org/10.1186/s40064-016-1799-z

[48] Gottman, J.M., Murray, J.D., Swanson, C.C., Tyson, R. and Swanson, K.R. (2005) The Mathematics of Marriage. Dy- 
namic Nonlinear Models. MIT Press, Massachusetts.

[49] Guastello, S.J. and Guastello, D.D. (2008) Dynamics of Attitudes and Genetic Processes. Nonlinear Dynamics, Psychology, and Life Sciences, 12, 75-86.

[50] May, R.M. (1976) Simple Mathematical Models with Very Complicated Dynamics. Nature, 26, $459-467$. http://dx.doi.org/10.1038/261459a0

[51] McBarnett, M. (1997) Complexity in the Evolution of Public Opinion. In: Kiel, D.L. and Elliott, E., Eds., Chaos Theory in the Social Science: Foundations and Applications, the University of Michigan Press, Ann Arbor, 165-196.

[52] Saperstein, A.M. (1997) The Prediction of Unpredictability: Applications of the New Paradigm of Chaos in Dynamical Systems to the Old Problem of the Stability of a System of Hostile Nations. In: Kiel, D.L. and Elliott, E., Eds., Chaos Theory in the Social Science: Foundations and Applications, the University of Michigan Press, Ann Arbor, 139-163.

[53] Saperstein, A.M. (1997) The Origin of Order and Disorder in Physical and Social Deterministic Systems. In: Eve, R.A., Horsfall, S. and Lee, M.E., Eds., Chaos, Complexity, and Sociology, Myths, Models and Theories, Sage Publications Inc., Thousand Oaks, 102-122

[54] Grossmann, S. and Mayer-Kress, G. (1989) Chaos in the International Arms Race. Nature, 337, 701-704. http://dx.doi.org/10.1038/337701a0

[55] Campbell, D.K. and Mayer-Kress, G. (1997) Chaos and Politics: Applications of Nonlinear Dynamics to Socio-Political Issues. In: Grebogi, C. and Yorke, J.A., Eds., The Impact of Chaos on Science and Society, United Nation University Press, New York, 18-62.

[56] West, B.J. (1997) Chaos and Related Things: A Tutorial. The Journal of Mind and Behavior, 18, 103-126.

[57] Dixon, R. (1994) The Logistic Family of Discrete Dynamic Models. In: Credy, J. and Martin, V., Eds., Chaos and Non-Linear Models in Economics, Theory and Applications, Edward Elgar, 44-69.

[58] Dendrinos, D. and Mullally, H. (1985) Urban Evolution: Studies in the Mathematical Ecology of Cities. Oxford University Press, New York.

[59] Braun, M. (1993) Differential Equations and Their Applications. Springer-Verlag, New York. http://dx.doi.org/10.1007/978-1-4612-4360-1

[60] Kostelich, E.J. and Armbruster, D. (1996) Introductory Differential Equations. From Linearity to Chaos. AddisonWesley, New York.

[61] Kaplan. D. and Glass, L. (1995) Understanding Nonlinear Dynamics. Springer-Verlag, New York. http://dx.doi.org/10.1007/978-1-4612-0823-5

[62] Bertuglia, C.S. and Vaio, F. (2003) Nonlinerità, Caos, Complessità. Bollati Boringhieri, Torino.

[63] Marion, R. (1999) The Edge of Organization. Sage Publications, Thousand Oaks.

[64] Elaydi, S.N. (1991) An Introduction to Difference Equations. Springer-Verlag, New York.

[65] Feigenbaum, M. (1978) Quantitative Universality for a Class of Non-Linear Transformations. Journal of Statistical Physics, 19, 25-52. http://dx.doi.org/10.1007/BF01020332

[66] Li, T. and Yorke, J.A. (1975) Period Three Implies Chaos. American Mathematical Monthly, 82, 985-992. http://dx.doi.org/10.2307/2318254

[67] Casti, J. (1994) Complexification. Explaining a Paradoxical World through the Science of Surprise. Harper Collins, New York.

[68] Bak, P. (1996) How Nature Works: The Science of Self-Organized Criticality. Springer, Berlin. http://dx.doi.org/10.1007/978-1-4757-5426-1

[69] Holland, J.H. (1995) Hidden Order: How Adaptation Builds Complexity. Addison-Wesley, Reading.

[70] Langton, C.G. (1990) Computation at the Edge of Chaos. Physica D, 42, 12-37. http://dx.doi.org/10.1016/0167-2789(90)90064-V

[71] Anderson, P.W. (1972) More Is Different. Science, 177, 393-396. http://dx.doi.org/10.1126/science.177.4047.393

[72] Gell-Mann, M. (1994) The Quark and the Jaguar. Adventures in the Simple and the Complex. Freeman W.H. and Company, New York.

[73] Horgan, J. (1996) The End of Science: Facing the Limits of Knowledge in Twilight of the Scientific Age. Addison Wesley, New York.

[74] Nicolis, G. (1989) Physics of Far-from-Equilibrium System and Self-Organization. In: Davies, P., Ed., The New Physics, Cambridge University Press, New York. 


\section{Submit or recommend next manuscript to SCIRP and we will provide best service for you:}

Accepting pre-submission inquiries through Email, Facebook, LinkedIn, Twitter, etc.

A wide selection of journals (inclusive of 9 subjects, more than 200 journals)

Providing 24-hour high-quality service

User-friendly online submission system

Fair and swift peer-review system

Efficient typesetting and proofreading procedure

Display of the result of downloads and visits, as well as the number of cited articles

Maximum dissemination of your research work

Submit your manuscript at: http://papersubmission.scirp.org/ 